\title{
Cholinergic Regulation of Arterial Pressure by the C1 Area of the Rostral Ventrolateral Medulla
}

\author{
Rachel Giuliano, David A. Ruggiero, Shaun Morrison, Paul Ernsberger, and Donald J. Reis \\ Division of Neurobiology, Cornell University Medical College, New York, New York 10021
}

In anesthetized, paralyzed rats intravenous administration of the acetylcholinesterase inhibitor physostigmine (PHY) $(100 \mu \mathrm{g} / \mathrm{kg})$ evoked a dose-related rise in arterial pressure (AP) and heart rate (HR) and an associated increase in sympathetic nerve activity (SNA). The responses to PHY were blocked by electrolytic lesions of, or microinjection of kainic acid into, a specific site in the rostral ventrolateral medulla containing a cluster of neurons immunoreactive for the adrenaline-synthesizing enzyme phenylethanolamine $\mathbf{N}$-methyltransferase and corresponding to the $\mathrm{C} 1$ area of the nucleus reticularis rostroventrolateralis (RVL). The $C 1$ area and its surround contain a heretofore unrecognized network of varicose neuronal processes and perikarya labeled immunocytochemically with a monoclonal antibody to the AChsynthesizing enzyme, choline acetyltransferase (CAT). PHY increased, by over 3 -fold, the spontaneous activity of reticulospinal cardiovascular neurons in the $c 1$ area which excite preganglionic sympathetic neurons in the intermediolateral spinal column. The effects of PHY on AP, SNA, and the discharge of reticulospinal neurons were blocked by systemic administration of the muscarinic antagonist scopolamine. Microinjections within the $\mathrm{C}_{1}$ area of the RVL of scopolamine, the $\mathrm{M}_{\mathbf{2}}$-selective muscarinic receptor antagonist AF-DX 116, or the high-affinity choline uptake inhibitor hemicholinium-3 blocked the pressor effects of PHY. The nicotinic antagonist hexamethonium and the $M_{1}$-selective muscarinic receptor antagonist pirenzepine were without effect. We conclude that (1) the Increases In AP, HR, and SNA elicited by the systemic administration of PHY result from the augmented action of ACh released from cholinergic terminals within the $C 1$ area of the RVL; (2) the locally released ACh acts through muscarinic receptors of the $M_{2}$ subtype within the $\mathrm{C}_{1}$ area to produce excitation of intrinsic reticulospinal sympathoexcitatory neurons, thereby increasing the activity of sympathetic preganglionic neurons and consequently elevating AP and HR; and (3) while the specific func-

\footnotetext{
Received May 11, 1988; revised Aug. 5, 19888; accepted Aug. 10, 1988.

This work was supported by NIH Grants HL 07378 and HL 18974 and an A.H.A. Established Investigatorship (D.A.R.). We thank Dr. Hector Cornejo for computer assistance, Muhammad Anwar for excellent technical support, Bill Feig for photographic assistance, Nancy Marmor and Hillary Rettig for their assistance in preparing the manuscript, Drs. Cory Abate and Tong H. Joh for their supply of PNMT antibody, and Boehringer-Ingelheim Corporation (Ridgefield, CT) for generous donations of pirenzepine and AF-DX 116

Correspondence should be addressed to Rachel Giuliano, Ph.D., Division of Neurobiology, Cornell University Medical College, 411 East 69th Street, New York, NY 10021 .

Copyright (C) 1989 Society for Neuroscience $0270-6474 / 89 / 030923-20 \$ 02.00 / 0$
}

tion of the cholinergic innervation of the $\mathrm{C} 1$ area in cardiovascular regulation is unknown, it may contribute to the tonic regulation of $\mathbf{A P}$.

The ventrolateral medulla (VLM) plays a crucial role in central cardiovascular control (see Ciriello et al., 1986; Reis et al., 1987; Ruggiero and Reis, 1988). Both anatomical and functional evidence suggest that the critical locus in arterial pressure (AP) regulation resides in a restricted zone of the VLM, the nucleus reticularis rostroventrolateralis (RVL), which surrounds and includes the rostral cluster of adrenergic neurons of the $\mathrm{Cl}$ group (Cl area of Hökfelt et al., 1974). A subdivision of the larger nucleus paragigantocellularis lateralis, the RVL is characterized by immunocytochcmical labeling of $\mathrm{C} 1$ neurons with antibodies to the adrenaline-synthesizing enzyme phenylethanolamine $N$-methyltransferase (PNMT) and projections from the nucleus tractus solitarii (Ross et al., 1984b, 1985; Ruggiero et al., 1985b). Neurons within the $\mathrm{Cl}$ area of the RVL innervate preganglionic neurons of the intermediolateral cell column (IML) of the spinal cord (Ross et al., 1981, 1984a; Milner et al., 1988a), are spontaneously active, and provide the excitatory input necessary for the maintenance of tonic sympathetic activity and AP (Brown and Guyenet, 1984; Ross et al., 1984b; Barman and Gebber, 1985; Granata et al., 1985; Morrison et al., 1988) and mediate major cardiovascular reflexes (Dampney and Moon, 1980; Willette et al., 1983b; Granata et al., 1985; Sun and Guyenet, 1985; Stornetta et al., 1989).

Acetylcholine (ACh) may play a role in the cardioregulatory functions of the VLM (Guertzenstein, 1973; Dev and Loeschcke, 1979). Recent evidence indicates that cholinergic agonists microinjected into the RVL (Giuliano et al., 1987; Willette et al., 1984) or applied to the subjacent ventral surface (Benarroch et al., 1986b) elevate AP and heart rate (HR) in the rat. The RVL has been implicated also in the pressor response to the acetylcholinesterase inhibitor physostigmine (PHY) administered intravenously (Giuliano et al., 1986; Punnen et al., 1986). That PHY acts in the RVL by enhancing the action of locally released $\mathrm{ACh}$ is supported by the observation that vasopressor responses to systemic or intraparenchymal PHY are blocked by focal microinjection of the muscarinic antagonist scopolamine (SCOP) (Willette et al., 1984; Giuliano et al., 1986, 1987; Punnen et al., 1986). Conceivably, it is the $\mathrm{Cl}$ area of the RVL that may be the site of the sympathoexcitatory actions of $\mathrm{ACh}$ : (1) The $\mathrm{Cl}$ area contains high levels of activity of the ACh-synthesizing enzyme choline acetyltransferase (CAT) (Arneric et al., 1986; Ernsberger et al., 1988b); (2) muscarinic receptors are abundant in the region (Ernsberger et al., 1988a, b); (3) release of $\mathrm{ACh}$ from micropunches of the $\mathrm{Cl}$ area is $\mathrm{Ca}^{2+}$-dependent and graded 
with respect to $\mathrm{K}^{+}$-evoked depolarization (Arneric et al., 1986); (4) microinjection sites at which cholinomimetics evoke pressor and tachycardiac effects correspond to the distribution of adrenaline neurons identified immunocytochemically (Giuliano et al., 1986, 1987); and (5) fibers of the C1 area abut directly upon the ventral medullary surface and brain-stem microvessels, where topically applied cholinergic agonists act to influence AP (Ruggiero et al., 1985b; Benarroch et al., 1986b; Ruggiero and Reis, 1988).

In the present investigation we examined morphophysiological substrates in the RVL underlying the vasopressor responses to intravenous PHY in the anesthetized rat. Utilizing immunocytochemical techniques in combination with microinjection and electrophysiological methods, we suggest a functional interaction between a newly described neural substrate and cardiovascular neurons in the $\mathrm{Cl}$ area of the RVL. We demonstrate that the site of action of PHY corresponds to the $\mathrm{Cl}$ area of the $\mathrm{RVL}$, that there exists a source of endogenous $\mathrm{ACh}$ in the rich plexus of varicose cholinergic processes in the region, that the pressor effects of $\mathrm{PHY}$ are mediated by muscarinic receptors of the $\mathrm{M}_{2}$ subtype within the RVL and that the cholinergic innervation of the region may contribute to the tonic regulation of AP. Preliminary results of this work have been presented in abstract form (Giuliano et al., 1986, 1987; Ruggiero et al., 1987).

\section{Materials and Methods}

General procedures

Experiments were performed on adult male Sprague-Dawley rats (325$375 \mathrm{gm}$ ) anesthetized with urethane $(1.35 \mathrm{gm} / \mathrm{kg}$, i.p.). A polyvinyl cannula (Tygon microbore 0.030 inch o.d.) was placed in the right femoral vein for injection of drugs, a polyethylene catheter (PE 50) was inserted into the right femoral artery for recording AP and HR, and the trachea was cannulated. The animal was paralyzed with $d$-tubocurarine $(0.1 \mathrm{mg} / \mathrm{kg}$, i.v., with hourly supplemental doses of $0.05 \mathrm{mg} / \mathrm{kg})$ and artificially ventilated on $100 \% \mathrm{O}_{2}$ (Harvard respirator). Additional anesthetic $(0.1 \mathrm{gm} / \mathrm{kg}, \mathrm{i} . \mathrm{v}$.) was given if an experiment exceeded $4 \mathrm{hr}$.

AP was recorded via a Statham P23 Db strain gauge transducer connected to a chart recorder (Grass model 7 Physiograph). HR was computed on-line by a cardiotachometer triggered by the AP. Body temperature was maintained at $37^{\circ} \mathrm{C}$ by a thermostatically regulated heat pad controlled by a rectal thermistor probe.

The animal was mounted in a stereotaxic frame (Kopf) with the head inclined downward by $45^{\circ}$ and the bite bar set at $-12 \mathrm{~mm}$. The occipital bone was removed and the atlanto-occipital membrane opened. The calamus scriptorius, visualized by incising the overlying dura, served as stereotaxic zero for rostral-caudal and lateral coordinates. The surface of the calamus served as the dorsoventral zero.

\section{Intramedullary microinjections and electrolytic lesions}

Microinjections. Intramedullary microinjections were made through glass micropipettes pulled from capillary tubing (i.d. $0.14 \mathrm{~mm}$, Corning) and broken back to a tip diameter of $40-60 \mu \mathrm{m}$. They were filled with agents dissolved in $0.9 \%$ sodium chloride and adjusted to $\mathrm{pH} 7.3-7.4$. Pipettes were mounted in a custom-tooled holder connected by polyethylene tubing to a mechanically regulated pneumatic injection system and were carried in a stereotaxic micromanipulator. The injection volume in all experiments was $50 \mathrm{nl}$.

In experiments that examined the effects of agents injected into the $\mathrm{Cl}$ area of the RVL upon the AP responses to i.v. PHY, the Cl area was first localized functionally by microinjection of L-glutamate (see below). The pipette was withdrawn and approximately 20 min later, a baseline response to PHY was obtained. The pipette was rinsed 10 times with distilled water, filled with test agent, and reinserted into the same track. Agent was administered and the effect upon a second dose of PHY established.

Functional localization of the $C I$ area of the $R V L$. In all studies in which agents were to be injected or lesions placed, the Cl area of the RVL was localized functionally by demonstration of a pressor response to the local microinjection of L-glutamate (Goodchild et al., 1982; Willette et al., 1983a; Ross et al., 1984b). Stereotaxic coordinates were approximately $2.0 \mathrm{~mm}$ rostral to calamus scriptorius, $2.0 \mathrm{~mm}$ lateral to midline and $3.0-3.5 \mathrm{~mm}$ below the dorsal surface of the brain stem. An elevation of AP of $30 \mathrm{~mm} \mathrm{Hg}$ after microinjection of $2 \mathrm{nmol}$ $\mathrm{L}$-glutamate in $50 \mathrm{nl}$ was taken as functional evidence that the cannula tip was in the $\mathrm{Cl}$ area.

Electrolytic lesions. Electrolytic lesions were made by passing an anodal DC current ( $500 \mu \mathrm{A}$ for $30 \mathrm{sec})$ from a constant-current source through an insulated stainless steel electrode (150 $\mu \mathrm{m}$ o.d.) with an exposed tip of about $150 \mu \mathrm{m}$. The cathode was a clip attached to a neck muscle. The electrode was directed stereotaxically in to the desired brainstem site.

Controls. In some experiments, control lesions or drug microinjections were made into the nuclei raphe obscurus and magnus, the nucleus gigantocellularis, the trigeminal complex, and the nucleus reticularis parvocellularis located at representative stereotaxic coordinates (at AP +2.0 according to Paxinos and Watson, 1986).

\section{Electrophysiological recordings}

Sympathetic nerve activity (SNA) and discharge rate of RVL-spinal vasomotor neurons were measured using methods described in detail elsewhere (Morrison et al., 1988). Animals (anesthetized, cannulated, paralyzed, and ventilated as described above) were placed in a stereotaxic apparatus and spinal investigation unit (Kopf). An occipital craniotomy and T1-T3 laminectomy were performed. Exposed nervous tissue was covered with a warm mixture of silicon lubricant and paraffin oil. A pneumothorax reduced respiration pump-related movements of tissue near the recording electrodes. To activate the baroreceptor reflex, brisk increases in AP were produced with injections of a bolus $(0.5 \mu \mathrm{g}$, i.v.) of phenylephrine.

Postganglionic SNA was recorded from the central cut end of the left splanchnic nerve dissected distal to the suprarenal ganglion in the region between the diaphragm and the adrenal gland. Nerve activity was recorded with platinum bipolar hooks in a monopolar configuration, amplified (Crass 7P3) and filtered between 1 and 50 H7. SNA and AP were continuously monitored on a polygraph. The electrocardiogram (ECG) was recorded with subcutaneous chest electrodes and a Schmidt-trigger circuit was used to derive standardized pulses coincident with the $\mathrm{R}$-wave of the ECG. Unit spikes were recorded on analog tape (HP 3968A) along with SNA, AP, and pulses derived either from the Rwave of the ECG or from stimuli applied to the spinal cord.

The spontaneous and evoked action potentials of individual neurons in the RVL were recorded extracellularly (AC coupled, 300-3000 Hz) with glass micropipettes (2-6 Ms at $1000 \mathrm{~Hz}$ ) filled with $2 \mathrm{M} \mathrm{NaCl}$ saturated with Fast green dye. The indifferent electrode was attached to the skull. Constancy of spike amplitude and contour was used to assess the unitary nature of the recordings. To monitor the discharge frequency of RVL units, standardized pulses were derived from their action potentials with a window discriminator and counted in $1 \mathrm{sec}$ bins with a ratemeter whose output was displayed on a polygraph (Grass 7D).

To identify antidromically RVL neurons with axons projecting to the IML of the spinal cord, stimuli ( $1 \mathrm{msec}$, cathodal) were delivered to the IML region of T 2 through a concentric bipolar electrode (Rhodes, SNE100) positioned $700 \mu \mathrm{m}$ below the dorsal root entry zone. Three criteria used to distinguish antidromic activation of RVL neurons (Lipski, 1981 Morrison et al., 1988) were (1) constant onset latency, (2) high following frequency, and (3) positive collision test. During these tests, pulses coincident with unit discharges were used to trigger an IBM-AT computer that delivered the desired stimulus configuration at a variable delay Spinal stimulus pulses were then amplified and passed through a constant-current unit (Grass PSIU6)

Data were analyzed with an IBM-AT computer using a DATA-Translation A/D board at a $1000 \mathrm{~Hz}$ sampling rate for SNA and AP. Programs were developed to perform post-R-wave analysis and spike-triggered averaging. The application of these averaging techniques to the characterization of RVL-spinal vasomotor neurons has been previously described (Barman and Gebber, 1985; Morrison et al., 1988).

In some animals, SCOP ( $1 \mathrm{mg} / \mathrm{kg}, \mathrm{i.v}$.) was given at the peak of the PHY response. The discharge rate of $R V L-s p i n a l$ vasomotor neurons following SCOP administration was expressed as the percentage of prePHY control values.

\section{Histology}

Localization of electrolytic lesion, electrophysiological recording, and microinjection sites. All lesion, electrophysiological recording, and mi- 
Table 1. Effects of electrolytic lesions of the $\mathrm{Cl}$ area on the pressor response to systemic PHY $(100 \mu \mathrm{g} / \mathrm{kg})$

\begin{tabular}{|c|c|c|c|c|c|}
\hline \multirow[b]{3}{*}{ Group } & \multirow[b]{3}{*}{$n$} & \multicolumn{4}{|c|}{ Mean arterial pressure $(\mathrm{mm} \mathrm{Hg})$} \\
\hline & & \multicolumn{2}{|l|}{ Before lesion } & \multicolumn{2}{|l|}{ After lesion } \\
\hline & & Resting & Response to PHY & Resting & Response to $\mathrm{PHY}$ \\
\hline Unilateral $\mathrm{Cl}$ area lesion & (4) & $100 \pm 8.4$ & $+60 \pm 16.2$ & $101 \pm 11.4$ & $+62 \pm 11.0$ \\
\hline Bilateral $\mathrm{Cl}$ area lesions & (6) & $83 \pm 8.5$ & $+48 \pm 5.4$ & $45 \pm 5.7^{a}$ & $+7 \pm 1.2^{a}$ \\
\hline Bilateral $\mathrm{C} 1$ area lesions and phenylephrine & (4) & $113 \pm 21.1$ & $+47 \pm 3.5$ & $91 \pm 4.7$ & $-7 \pm 4.8^{a}$ \\
\hline Bilateral raphe area lesions & (6) & $106 \pm 2.4$ & $+53 \pm 8.0$ & $117 \pm 11.8$ & $+41 \pm 5.5$ \\
\hline
\end{tabular}

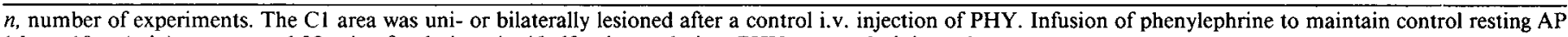
(about $10 \mu \mathrm{g} / \mathrm{min}$ ) commenced $20 \mathrm{~min}$ after lesion. At $45-60 \mathrm{~min}$ postlesion, PHY was readministered.

" $p<0.05$ vs. "before lesion."

croinjection sites were verified histologically. The positions of recording sites were marked with electrophoretic dye deposites (15 $\mu \mathrm{A}$ cathodal DC for $20 \mathrm{~min}$; see Electrophysiological recordings) and examined in relationship to the $\mathrm{Cl}$ adrenergic neurons following immunocytochemical localization of PNMT (see Immunocytochemistry). To identify microinjection sites, in all experiments (except those in which the brain was to be processed for immunocytochemistry or autoradiography), the pipette was removed at the end of an experiment and refilled with $1 \%$ Fast green or $25 \%$ India ink; it was reinserted and the dye deposited at the microinjection site(s). The animal was killed by administration of a bolus of saturated $\mathrm{KCl}$, the brain removed, rapidly frozen in Freon, and sectioned at $25 \mu \mathrm{m}$ on a cryostat. Sections were subsequently stained with thionin and examined microscopically.

Immunocytochemistry. At the end of all lesion and electrophysiological studies and some microinjection experiments an extra dose of urethane $(0.1 \mathrm{gm} / \mathrm{kg}, \mathrm{i} . \mathrm{v}$.) was administered and the rat sacrificed by perfusion through the heart with $4 \%$ paraformaldehyde in $0.1 \mathrm{~m}$ phosphate buffer. Because microinjected Fast green or India ink diffuse from histological sections during immunocytochemical processing, in microinjection studies the pipette was refilled with an indelible dye extracted from the Sharpie ${ }^{\circledR}$ marking pen (High Intensity Ink, Sanford Co., Bellewood, IL) and diluted 3:2 with absolute ethanol. Dye was deposited at the microinjection site(s) prior to intracardiac perfusion. Frozen transverse sections were taken through the medulla at $25 \mu \mathrm{m}$ intervals with a sliding microtome and processed for immunocytochemical localization of PNMT or CAT by the peroxidase-antiperoxidase technique of Sternberger (1979) according to procedures published previously (Ruggiero et al., 1985b, 1987). Polyclonal antiserum was produced in rabbits against PNMT purified from bovine adrenal medulla as previously described (Joh and Goldstein, 1973; Park et al., 1982; Joh and Ross, 1983). CAT was localized with monoclonal antisera produced in rat-mouse hybridomas against porcine enzyme (Boehringer-Mannheim Biochemicals) and tested for specificity by previously described methods (Eckenstein et al., 1981; Eckenstein and Thoenen, 1982), including preabsorption of primary antiserum with porcine CAT coupled to Sepharose $4 \mathrm{~B}$, which prevented staining. In the present experiments, immunocytochemical specificity was demonstrated by the absence of immunoreactivity in sections incubated with normal rat serum instead of antiCAT primary antibody.

Sections were examined by bright- and dark-field illumination. The location of labeled cells was plotted with the aid of a camera lucida attached to a Leitz microscope.

Autoradiographic mapping of drug distribution. The distribution of 3 nmol ${ }^{3} \mathrm{H}$-SCOP ( $N$-methyl derivative; diluted to $0.33 \mathrm{Ci} / \mathrm{mmol}$ with unlabeled SCOP) unilaterally injected into the RVL ( $50 \mathrm{nl}$ ) was assessed by autoradiography. Approximately $8-10 \mathrm{~min}$ after microinjection of the agent, the rat was killed by decapitation and the brain rapidly removed and frozen in liquid Freon at $-20^{\circ} \mathrm{C}$. The hindbrain was mounted on a microtome chuck using Lipshaw $\mathrm{M}-1$ mounting medium and sectioned in a cryostat maintained at $-18^{\circ} \mathrm{C}$. Serial $10 \mu \mathrm{m}$ sections were thaw-mounted onto glass slides precoated with gelatin/chrome-alum. Alternate sections were fixed in formalin and stained with thionin for anatomical reference. Slides for autoradiographic mapping of the injection site were dried in a vacuum desiccator for $48 \mathrm{hr}$ prior to apposition to tritium-sensitive film (LKB Ultrofilm ${ }^{\circledR}$ ). Dried slides were arranged in an X-ray cassette alongside slides bearing $10 \mu \mathrm{m}$ sections of tritium standards (Amersham) designed to reproduce the autoradiographic ef- ficiency of brain gray matter (Geary and Wooten, 1983). After an exposure of $9 \mathrm{~d}$ at $4^{\circ} \mathrm{C}$ over desiccant, the film was developed (Kodak D19, $5 \mathrm{~min}$ ). Autoradiograms were processed using an image analysis system (Eyecom II, Microvax II) as previously described (Ernsberger et al., 1988a, b; Iadecola et al., 1983). To provide anatomic registration, the digitized and shade-corrected image of the injection site was superimposed upon an outline of medullary landmarks derived from the adjacent thionin-stained section.

\section{Drugs}

The following drugs were used (Sigma Chemical Co., St. Louis): L-glutamate (L-glutamate as monosodium salt), hemicholinium-3 (HC-3) hexamethonium bromide, L-phenylephrine hydrochloride, PHY (as salicylate for i.v. administration, as sulfate for intraparenchymal injection), scopolamine hydrobromide (SCOP). ${ }^{3} \mathrm{H}-\mathrm{SCOP}(N$-methyl derivative, $85 \mathrm{Ci} / \mathrm{mmol}$ ) was obtained from New England Nuclear (Boston), stored in ethanol at $-20^{\circ} \mathrm{C}$, and dried under a nitrogen stream prior to use. Pirenzepine and AF-DX 116 were donated by Boehringer-Ingelheim (Ridgefield, CT).

\section{Data evaluation}

Statistical evaluation was carried out using paired and unpaired Student's $t$ test or a 1 -way analysis of variance with Newman-Keuls multiple range test. Results are expressed as means \pm SEM.

\section{Results}

Effects of lesions of the C1 area of the RVL on vasopressor responses to $\mathrm{PHY}$

Vasopressor responses to systemic administration of $P H Y$

In anesthetized, paralyzed, and ventilated rats, PHY (100 $\mu \mathrm{g})$ $\mathrm{kg}$, i.v.) characteristically elicited changes in HR, SNA, and AP. The first response was a bradycardia, which appeared at approximately $30-60 \mathrm{sec}$ after administration of the drug (Fig. 1A). Within 2-3 min the bradycardia reversed and HR gradually rose, peaking at 5-10 min with a return to baseline by $45 \mathrm{~min}$. After a latency of 1-2 min, in parallel with the tachycardia, SNA and AP began to increase, peaked at $3-5 \mathrm{~min}$, and returned to baseline by $30-45$ min (Figs. $1 A ; 2, A, B$ ). The initial fall in HR was blocked by methylatropine $(1 \mathrm{mg} / \mathrm{kg}, \mathrm{i} . \mathrm{v}$.), indicating that it was due to a peripheral cardiovagal mechanism (Brezenoff and Giuliano, 1982).

The vasopressor response to PHY was dose-dependent (Fig. 3). The threshold dose was approximately $4.1 \mu \mathrm{g} / \mathrm{kg}(0.01 \mu \mathrm{mol} /$ $\mathrm{kg})$, with maximal responses obtained at $413 \mu \mathrm{g} / \mathrm{kg}(1.0 \mu \mathrm{mol} /$ $\mathrm{kg})$. At the highest dose tested, $4134 \mu \mathrm{g} / \mathrm{kg}(10 \mu \mathrm{mol} / \mathrm{kg})$, the initial rise in AP often was followed, within $30 \mathrm{sec}$, by a sudden collapse in AP and marked bradycardia (Figs. $1 B, 3$ ). At this dose, 4 of 9 animals died with cardiac arrest within $30-90 \mathrm{~min}$; the remainder recovered (Fig. $1 B$ ).

In the subsequent experiments, animals received $100 \mu \mathrm{g} / \mathrm{kg}$ 

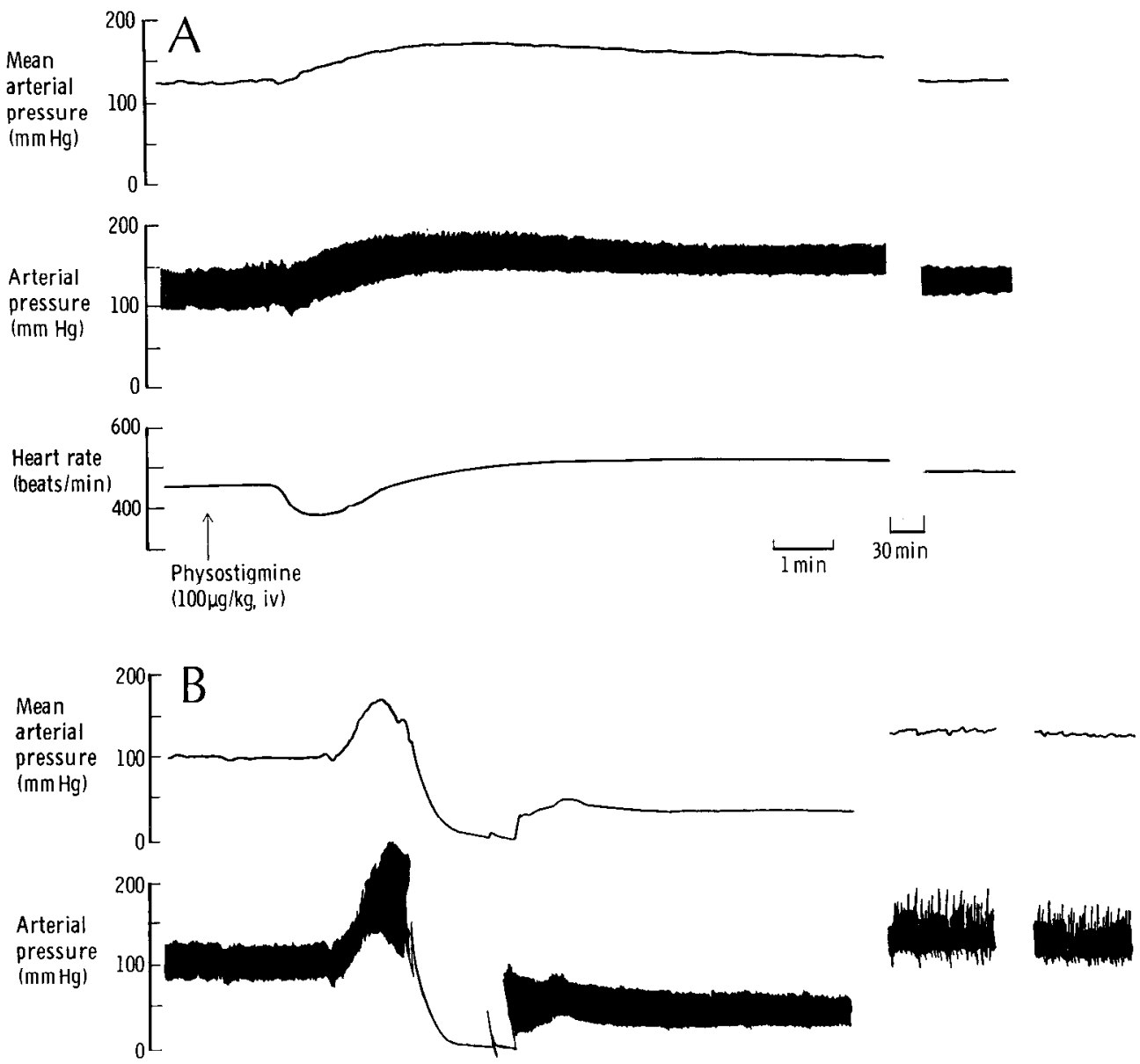

Figure 1. Effect of intravenous injection of physostigmine (PHY) on arterial pressure (AP) and heart rate (HR). $A$, Mean AP, pulsatile AP, and HR recording from a typical urethane-anesthetized rat injected with $100 \mu \mathrm{g} / \mathrm{kg}$ PHY. At the highest dose tested (4134 $\mu \mathrm{g} / \mathrm{kg}$ ), 4 of 9 animals died within 30 90 min without recovering baseline AP. $B$, In a typical surviving rat, AP returned to pretreatment level after approximately $30 \mathrm{~min}$.

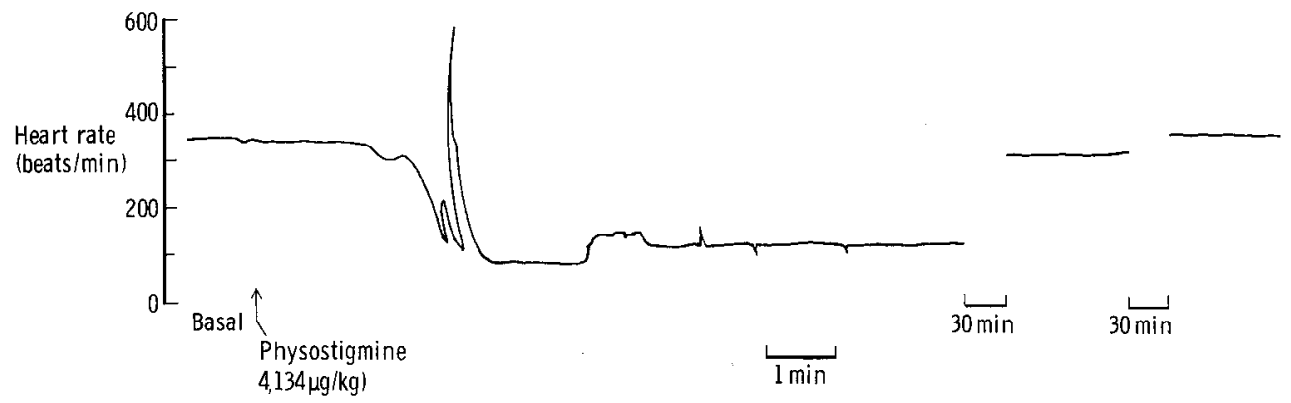

$(0.24 \mu \mathrm{mol} / \mathrm{kg})$ of PHY, a dose that evoked stable and reproducible responses (see Table 2).

Effects of electrolytic lesions of the C1 area of the RVL on the pressor response to $\mathrm{PHY}$

Unilateral lesions. Unilateral lesions of the $\mathrm{Cl}$ area had no effect on resting AP or the pressor response to PHY (Table 1). The typical biphasic HR response to PHY [fall of $47 \pm 5$ beats per minute (bpm) followed by an increase of $54 \pm 4 \mathrm{bpm}$ ] was unaltered (fall of $38 \pm 11 \mathrm{bpm}$ followed by an increase of 48 $\pm 15 \mathrm{bpm} ; p>0.05, n=4$ ). The failure of a unilateral lesion to modify resting or drug-initiated changes in AP is in agreement with other studies showing that after unilateral damage the contralateral $\mathrm{C} 1$ area is sufficient to provide tonic and reflex control of the circulation by the brain stem (Granata et al., 1985; Benarroch et al., 1986a).

Bilateral lesions. Bilateral lesions of the $\mathrm{Cl}$ area, but not the nuclei raphe magnus or obscurus (Table 1), resulted in a dra- matic fall in AP. AP dropped to approximately $45 \mathrm{~mm} \mathrm{Hg}$, a level comparable to that obtained by spinal cord transection (Ross et al., 1983, 1984b; Granata et al., 1985). After bilateral lesions, PHY still elicited the initial bradycardia $(-47 \pm 8 \mathrm{bpm}$ in controls vs. $-37 \pm 10 \mathrm{bpm}$ after lesions; $p>0.05, n=6$ ), but the elevations of AP and HR (Table 1) were abolished. The disappearance of the sympathoexcitatory responses to PHY resulting from $C 1$ area lesions could not be attributed to the associated fall of AP: Even when AP was maintained by phenylephrine (approximately $10 \mu \mathrm{g} / \mathrm{min}$, i.v.) at levels comparable to those of untreated rats, PHY still failed to elevate AP or HR (Table 1).

\section{Relationship of lesions to the $\mathrm{Cl}$ area}

Immunocytochemical localization of CAT in the RVL. We examined immunocytochemically the distribution of cholinergic processes and perikarya in the RVL (Fig. 4) in relation to the rostral cell group of adrenergic neurons of the $\mathrm{Cl}$ area in normal 

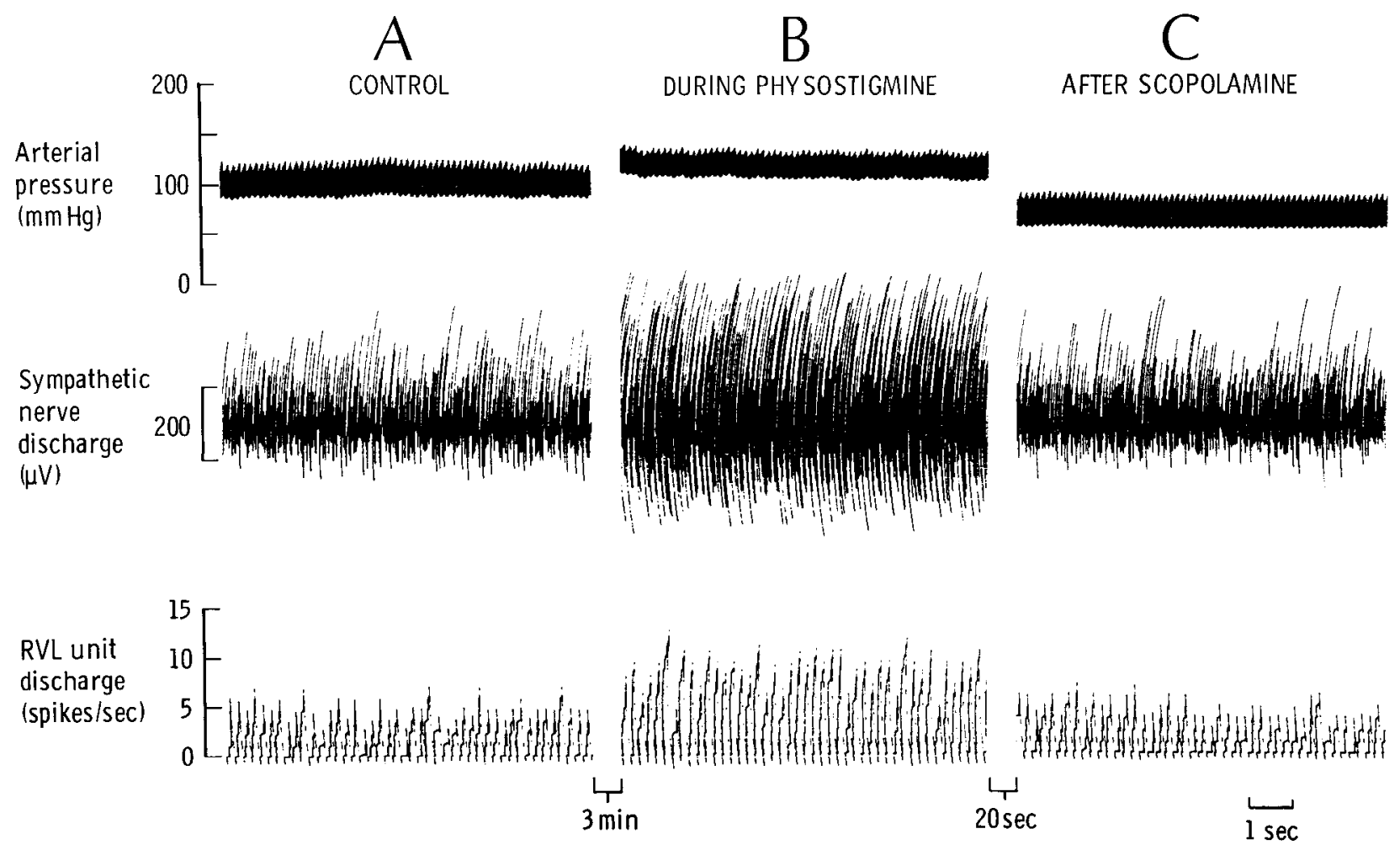

Figure 2. Record of a representative experiment showing the effect of systemic injection of physostigmine (PHY) or scopolamine on arterial pressure (AP), sympathetic nerve activity (SNA), and firing frequency of antidromically identified unit in nucleus reticularis rostroventrolateralis (RVL). $A$, Resting levels of activity in a urethane-anesthetized, paralyzed, and artifically ventilated rat. $B$, Peak response to PHY (100 $\mu \mathrm{g} / \mathrm{kg}) 3$ min after i.v. injection. $C$, Maximal decrease in AP, SNA, and RVL unit discharge $20 \mathrm{sec}$ after scopolamine (1 $\mu \mathrm{g} / \mathrm{kg})$ administered i.v. during the peak response to PHY.

unlesioned rats by using antibodies to CAT and PNMT. This region, which includes a rostral portion of the $\mathrm{Cl}$ adrenergic cell group of Hökfelt et al. (1974) (the cell cluster and lateral condensation as defined by Ruggiero et al., 1985b, and Ruggiero and Reis, 1988), is bordered dorsally (and dorsolaterally) by the nucleus ambiguus (NA) (and cells of the nucleus reticularis parvocellularis), laterally by the nucleus pars oralis of the trigeminal complex, ventrally by an area of the ventral subpial surface, and medially by the nucleus gigantocellularis and the inferior olive.

Alternate serial sections through the medulla oblongata labeled immunocytochemically for PNMT and CAT were compared. The RVL, including the $\mathrm{C} 1$ area, contained an especially high density of cholinergic (CAT-immunoreactive) processes, including small punctate terminal-like varicosities as confirmed by electron microscopy (Milner et al., 1987a) and thicker axons in passage and dendrites. These elements defined a field visualized under dark-field optics that conformed to the pyramidalshaped substructure of the RVL, as described by Ruggiero and Reis (1988), and partially overlapped PNMT-labeled perikarya in the $\mathrm{Cl}$ area and cells in the apex of the RVL directly underlying the compact division of the NA (Fig. 5). One group of thick immunoreactive processes (dendrites) extended ventrally into the RVL from cholinergic cell bodies in the compact and semicompact divisions of the NA (see Fig. 5, inset). A dense cluster of neurons labeled for CAT was detected along the medial border of the RVL adjacent to and contiguous with the nucleus raphe magnus. CAT-labeled perikarya were distributed ventromedially and, to a lesser extent, ventrally to the PNMT cell bodies of the $\mathrm{Cl}$ area, and showed little or partial overlap with the $\mathrm{Cl}$ adrenergic neurons (Fig. 4, right side). The cholinergic neurons differed from those containing PNMT in that they were (1) more medially disposed and compactly organized; (2) individually distinguishable from those staining for PNMT; (3) overall smaller in diameter (approximately 16-30 $\mu \mathrm{m}$ ); (4) oriented along several different axes, in contrast to the primarily diagonally horizontal orientation of the PNMT-immunoreactive neurons in the RVL; and (5) lay closer to the ventromedullary surface. Other CAT-immunopositive perikarya and fibers were traced along the ventral subpial surface and within the adjacent medullary raphe (Fig. 5).

Localization of effective lesions. In all 6 cases in which electrolytic lesions blocked the pressor and tachycardiac responses to PHY, the $\mathrm{Cl}$ area of the RVL was destroyed (Fig. 6A). The location of a typical lesion is shown in Figure $6 B$. Here, in a section stained immunocytochemically for CAT, the lesion damaged the region corresponding to the $\mathrm{Cl}$ area of the RVL underlying the compact division of NA and ventrolateral aspect of the nucleus reticularis parvocellularis. This particular lesion was medial to the trigeminal complex, lay just above the ventral subpial surface, and was lateral to without damaging the nucleus gigantocellularis pars ventralis et lateralis and the rostral pole of the inferior olivary nucleus. The cluster of cholinergic cell bodies lying medial to the $\mathrm{Cl}$ area was intact, whereas the CATlabeled field of punctate varicosities within the $\mathrm{Cl}$ zone was destroyed. In other cases, there was variable damage to either the NA and the parvocellular reticular nucleus or regions of the RVL adjacent to the $\mathrm{C} 1$ area.

A typical control lesion of the nuclei raphe magnus and obscurus is seen in Figure $6 C$. This, as well as in other control lesions which were limited to the nucleus gigantocellularis (also 

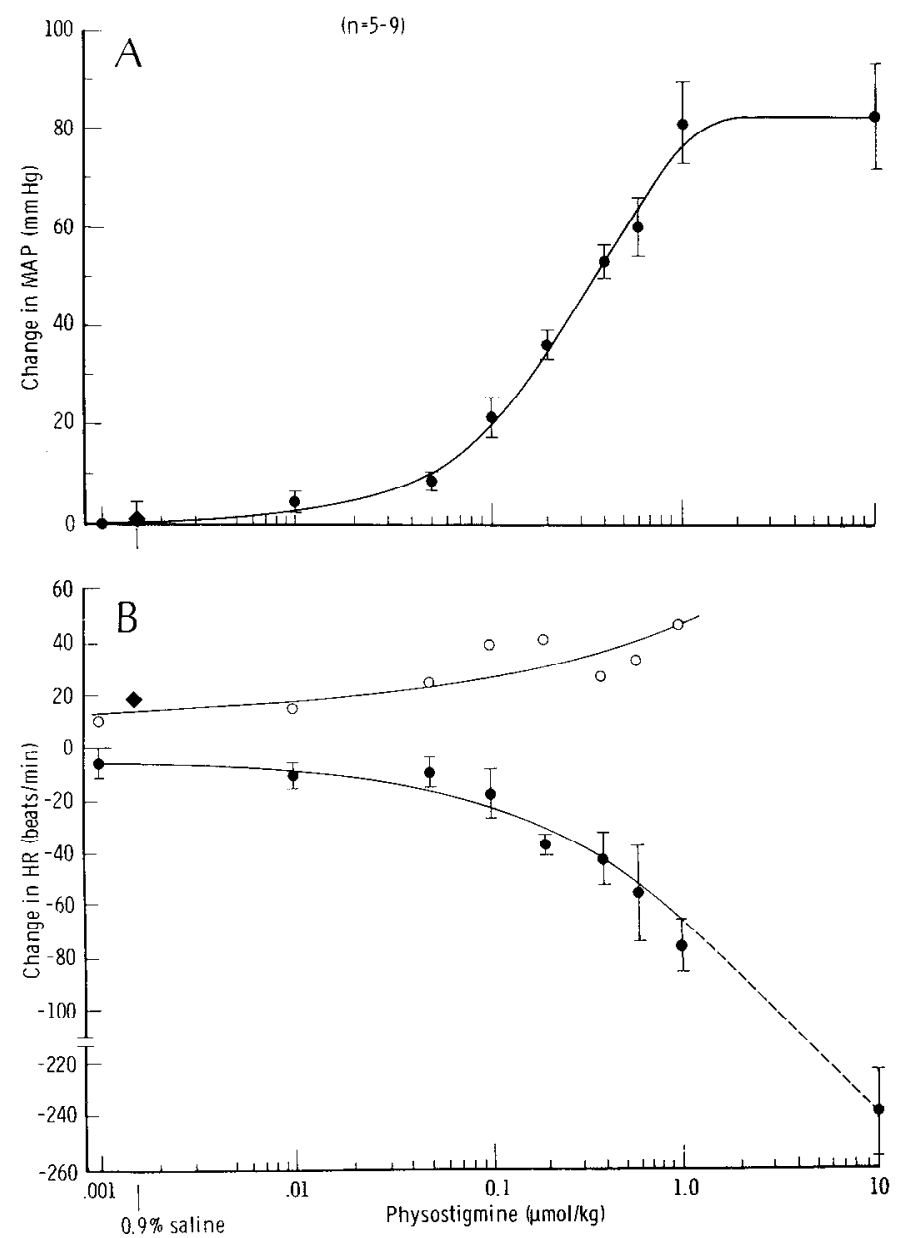

Figure 3. Effect on mean arterial pressure $(M A P)$ and heart rate $(H R)$ of various doses of physostigmine (PHY) injected intravenously. The vertical lines indicate the SEM. With the exception of the highest dose, each point $(n=5-7)$ represents the maximal increase in AP developing within 3-5 min of injection $(A)$ or the peak bradycardiac (filled circles) and tachycardiac (open circles) responses occurring 1-2 and 5-10 min, respectively, after injection $(B)$. The effects of vehicle $(0.9 \%$ saline; 0.1 $\mathrm{ml} / 100 \mathrm{gm}$ body weight) on MAP and HR are indicated by the diamond. At $10 \mu \mathrm{mol} / \mathrm{kg}(n=9)$, the vasopressor response to PHY was biphasic; only the initial rise in AP, lasting up to $1-1.5 \mathrm{~min}$ is shown. This was followed within 2-5 min by a marked fall in AP (46 $\pm 5 \mathrm{~mm} \mathrm{Hg})$ and death in $4 / 9$ animals. In surviving rats, AP recovered to baseline in about $30 \mathrm{~min}$. At $10 \mu \mathrm{mol} / \mathrm{kg}$, pronounced bradycardia, without subsequent tachycardia, was observed.

involving neurons of the lateral wings of the nucleus raphe magnus), the trigeminal complex or the nucleus reticularis parvocellularis, had no effect on the pressor response to PHY.

Overall, these findings indicate that the integrity of both $\mathrm{Cl}$ areas of the RVL is necessary for the expression of the increase in AP and HR, but not the bradycardia, clicitcd by systemic administration of PHY, and that the abolition of the responses requires topographically specific lesions.

Effects of bilateral microinjection of kainic acid into the $\mathrm{C} 1$ area on vasopressor responses to PHY

To establish that the effects of electrolytic lesions of the RVL on the PHY-evoked pressor responses were the result of inactivation of local cell bodies, we microinjected the excitotoxin kainic acid $(\mathrm{KA} ; 1 \mathrm{nmol} / 50 \mathrm{nl})$ bilaterally into the $\mathrm{Cl}$ area before administering PHY. At low doses, KA first stimulates, then
Table 2. Effect of bilateral microinjection of kainic acid (1 nmol) into the $\mathrm{Cl}$ area on the pressor response to PHY $(100 \mu \mathrm{g} / \mathrm{kg})$

\begin{tabular}{|c|c|c|c|c|}
\hline \multirow[b]{2}{*}{ Treatment } & \multirow[b]{2}{*}{$n$} & \multirow[b]{2}{*}{$\begin{array}{l}\text { Resting MAP } \\
(\mathrm{mm} \mathrm{Hg})\end{array}$} & \multicolumn{2}{|c|}{$\begin{array}{l}\text { Increase in AP } \\
\text { after PHY }\end{array}$} \\
\hline & & & $(\mathrm{mm} \mathrm{Hg})$ & $\begin{array}{l}\text { \% } \\
\text { control }\end{array}$ \\
\hline Saline & 5 & & & \\
\hline Before injection & & $92 \pm 8.3$ & & \\
\hline After $30 \mathrm{~min}$ & & $80 \pm 10.2$ & $49 \pm 12.0$ & 100 \\
\hline After $60 \mathrm{~min}$ & & $83 \pm 7.1$ & $60 \pm 13.0$ & 126 \\
\hline After $90 \mathrm{~min}$ & & $82 \pm 2.5$ & $49 \pm 7.2$ & 114 \\
\hline Kainic acid & 6 & & $40 \pm 5.0$ & 102 \\
\hline Before injection & & $106 \pm 4.3$ & $46 \pm 7.1$ & 100 \\
\hline After $30 \mathrm{~min}$ & & $97 \pm 8.1$ & $17 \pm 8.6^{a}$ & 37 \\
\hline After $60 \mathrm{~min}$ & & $55 \pm 5.2^{t}$ & $-3 \pm 4.4^{\prime \prime}$ & -6 \\
\hline After $90 \mathrm{~min}$ & & & & \\
\hline+ phenylephrine & & $105 \pm 5.9$ & $7 \pm 8.5^{b}$ & 16 \\
\hline
\end{tabular}

Control animals were injected bilaterally with $0.9 \% \mathrm{NaCl}$ solution $(50 \mathrm{nl} / \mathrm{side}) . n$ number of experiments; MAP, mean arterial pressure (mm Hg). Phenylephrine was infused at a dose sufficient to restore baseline AP (about $10 \mu \mathrm{g} / \mathrm{min}$ ).

$a p<0.05$ vs. control.

$p<0.01$ vs. control.

inactivates by depolarizing local neurons without affecting fibers of passage (Coyle et al., 1978; Curtis and Malik, 1985).

KA $(n=6)$, but not vehicle $(n=5)$, microinjected into the $\mathrm{C} 1$ area first increased $\mathrm{AP}(+68 \pm 15$ vs. $+4 \pm 6 \mathrm{~mm} \mathrm{Hg} ; p$ $<0.05$ ) within 5-10 min. The hypertension persisted for about $20 \mathrm{~min}$ and was followed, over $60 \mathrm{~min}$, by a gradual decline of AP to about $55 \mathrm{~mm} \mathrm{Hg}$ (Table 2). This value is comparable to that produced by spinal cord transection (Ross et al., 1983, 1984b; Granata et al., 1985). At $30 \mathrm{~min}$ after the local administration of KA, when AP was declining from peak levels and had rcached levels corresponding to that of the untreated animals, the pressor response to PHY was reduced by two-thirds (Table 2). By 60 min, when AP was maximally depressed, PHY was ineffective. Maintaining AP by infusion of phenylephrine failed to restore the pressor response (Table 2). Injections of KA into the raphe nuclei did not alter responses to PHY. In all animals the sites of microinjection were highly restricted to the region of the RVL containing the adrenergic C1 group (Fig. 7). Thus, the central vasopressor action of PHY depends upon the integrity of intrinsic neurons within the $\mathrm{Cl}$ area of the RVL.

\section{Effects of PHY upon discharge of vasomotor neurons in} the RVL

\section{Identification of caradiovascular RVL-spinal neurons}

Experiments were undertaken to establish if PHY would excite reticulospinal cardiovascular neurons of the RVL which presumably mediate sympathoexcitation from this region (Brown and Guyenet, 1984; Barman and Gebber, 1985; Morrison et al., 1988).

The activity of one RVL-spinal vasomotor neuron was studied in each of 8 rats. The criteria for the antidromic identification and cardiovascular characterization of these neurons are illustrated in Figure 8. Each RVL neuron responded to electrical stimulation $(60-400 \mu \mathrm{A})$ of the IML at the second thoracic segment (Morrison et al., 1988) with a constant onset latency (Fig. 8A1). These ranged from 6.4 to $23.0 \mathrm{msec}$, which corresponded to a mean spinal conduction velocity of $3.6 \pm 0.3$ 


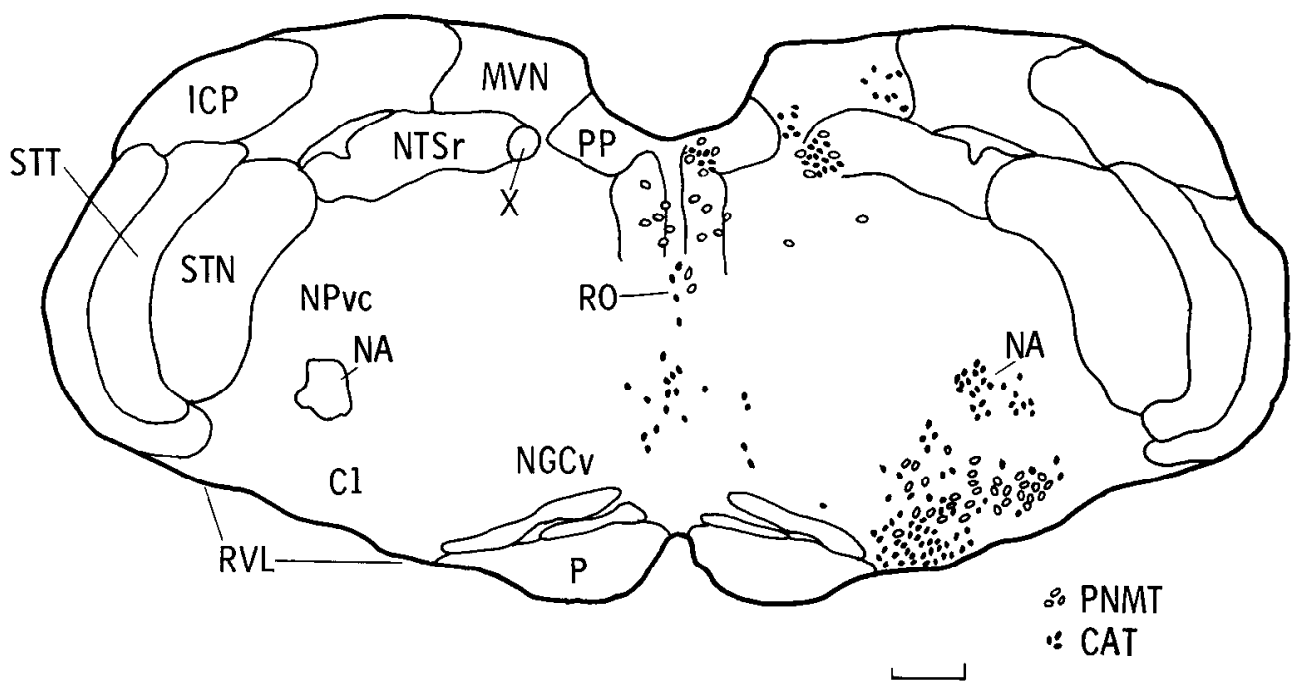

Figure 4. Camera lucida drawing of a coronal section through the rostral medulla showing distribution of neurons immunoreactive for the adrenaline-synthesizing enzyme PNMT and the acetylcholine-synthesizing enzyme CAT. Most neurons labeled for CAT were located in the ventromedial aspect of the nucleus reticularis rostroventrolateralis $(R V L)$. These cells were primarily ventral and medial to neurons of the $\mathrm{Cl}$ adrenergic group immunoreactive for PNMT. Other cells were labeled for CAT in the nucleus ambiguus $(N A)$, dorsal motor nucleus of the vagus $(X)$, raphe obscurus $(R O)$, and vestibular complex $(M V N)$. Other abbreviations: $C 1$, area of the rostral ventrolateral medulla containing PNMT-immunoreactive perikarya; $C A T$, choline acetyltransferase; $I C P$, inferior cerebellar peduncle; $N G C v$, nucleus gigantocellularis pars ventralis; $N P v C$, nucleus reticularis parvocellularis; $N T S r$, nucleus tractus solitarii, rostral division; $P$, pyramid; $P N M T$, phenylethanolamine $N$-methyltransferase; $P P$, nucleus prepositus; $S T N$, spinal trigeminal nucleus; $S T T$, spinal trigeminal tract. Scale bar, $465 \mu \mathrm{m}$.

$\mathrm{m} / \mathrm{sec}(n=8)$. An example of the collision test used to confirm the antidromic nature of the responses of RVL neurons to spinal stimulation is seen in Figure $8 A$. In this case, the critical delay was $12.8 \mathrm{msec}$ (Fig. 8, $A 1, A 2$ ), the onset latency of the unit response was $11.4 \mathrm{msec}$, and the axonal refractory period was $1.4 \mathrm{msec}$ (Fig. 8, $A 3, A 4$ ) as determined with the dual shock method (Swadlow, 1982). Thus, the critical delay was equal to the sum of the onset latency and the axonal refractory period, satisfying the requirements of the collision test.

To establish a role for RVL-spinal neurons in determining tonic sympathetic discharge, cross-correlational spike-triggered averaging (Gootman et al., 1975; Gebber and Barman, 1981; Morrison et al., 1988) was used to determine the temporal relationship between the firing of RVL-spinal neurons and cardiac-related bursts in SNA. The average of splanchnic SNA following RVL unit spikes (time 0, Fig. 8BI) had the period of the cardiac cycle $(112 \mathrm{msec}$, see Fig. $8 C)$, indicating that the discharges of RVL-spinal neurons are most likely to occur at a point preceding the tonic, cardiac-related bursts in SNA. Similar averages triggered by a random pulse train were flat, indicating the lack of a correlation between such pulse trains and SNA.

Using post-R-wave analysis, the relationship of RVL-spinal unit activity and SNA to the cardiac cycle was examined to determine if they were influenced by the baroreceptor reflex activation occurring during each systolic pressure rise. The post$\mathrm{R}$-wave interval histogram of the activity of this RVL-spinal neuron (Fig. $8 C$, lower trace) indicates a dramatic decrease in the discharge probability of this neuron following each AP pulse. That the baroreceptor modulation of RVL unit activity is transmitted to the splanchnic SNA is suggested by the parallel but delayed rhythm in the post-R-wave average of SNA (Fig. $8 C$, middle trace).

To examine more directly the action of baroreceptors on RVLspinal neurons, the effects of a rapid increase in AP evoked by i.v. injection of phenylephrine were examined. As illustrated in
Figure $8 D$, rapid elevations in AP completely inhibited the firing of RVL-spinal vasomotor neurons with an associated simultaneous suppression of SNA. These results strongly support the function of RVL-spinal neurons in sympathoexcitatory networks maintaining basal sympathetic tone. In agreement with our previous study (Morrison et al., 1988), all 8 neurons were restricted to the RVL and were surrounded by PNMT-immunoreactive cell bodies of the $\mathrm{C} 1$ adrenergic group. This finding suggests that such neurons mediate the potent cardiovascular responses evoked from the $\mathrm{Cl}$ area of the RVL (Ross et al., 1984b; Granata et al., 1985).

\section{Effects of PHY on neuronal discharge}

We determined the effect of i.v. administration of PHY (100 $\mu \mathrm{g} / \mathrm{kg}$ ) on the firing frequency of one RVL-spinal vasomotor neuron in each rat. Changes in discharge rate, expressed as a percentage of control, were calculated by dividing the mean discharge frequency during the 20 sec period at the peak of the PHY response by that during a similar period just prior to drug injection.

As illustrated in Figure 2, i.v. administration of PHY resulted in a consistent pressor response that was accompanied by an increase in splanchnic SNA and in the discharge rate of RVLspinal vasomotor neurons. The peak increases in both neuronal and sympathetic nerve discharge occurred 3-4 min after PHY injection and were maintained at this level for 2-3 min before returning to baseline in $30-45 \mathrm{~min}$. The changes in the discharge frequency of RVL-spinal neurons $(n=8)$ are shown in Table 3 . Following $P H Y$, the mean firing rate of RVL-vasomotor neurons was increased to $329 \pm 54 \%$ of that prior to the injection. This augmentation in medullospinal sympathoexcitatory drive was reflected in a clear increase in splanchnic SNA (not quantitated) and a rise in $\mathrm{AP}$ of $45 \pm 7 \mathrm{~mm} \mathrm{Hg}$. Moreover, the increases in RVL vasomotor unit activity were maintained during the pressor response, indicating that PHY reduces the ef- 

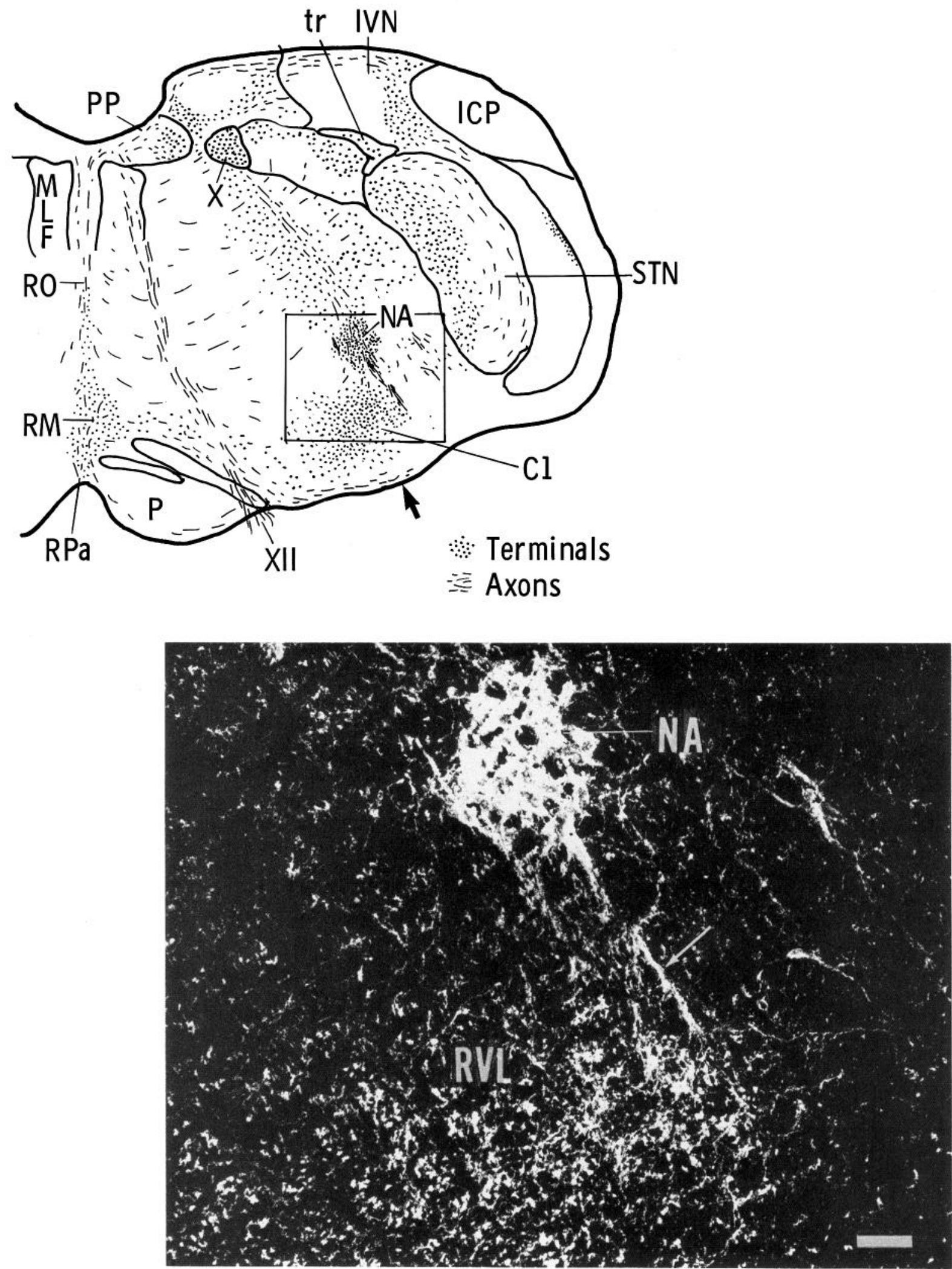

Figure 5. Camera lucida drawing of a coronal section through the rostral medulla showing the distribution of putative terminals (punctate varicosities) and axons labeled for CAT (no immunoreactive perikarya are indicated). A major terminal field occurred in an area of the nucleus reticularis rostroventrolateralis $(R V L)$ overlapping the $\mathrm{Cl}$ area (see Fig. 4) and underlying the nucleus ambiguus $(N A)$. The distribution of punctate processes conforming to the $R V L$ substructure was visualized under dark-field optics. The distribution of this field coincided with microinjection sites at which muscarinic antagonism or ACh synthesis inhibition blocked pressor responses to systemic administration of physostigmine (see Tables 4 and 5). Inset, Dark-field photomicrograph of the terminal field in the $R V L$ indicated by brackets. Note labeled processes (dendrites) extending into the $R V L$ from CAT-labeled cell bodies in the $N A$. Abbreviations: $I V N$, inferior vestibular nucleus; $M L F$, medial longitudinal fasciculus; $R M$, raphe magnus; $R P a$, raphe pallidus; $t r$, tractus solitarius; $X I I$, rootlets of hypoglossal nerve. Scale bar, $140 \mu \mathrm{m}$. See Figure 4 for additional abbreviations. 

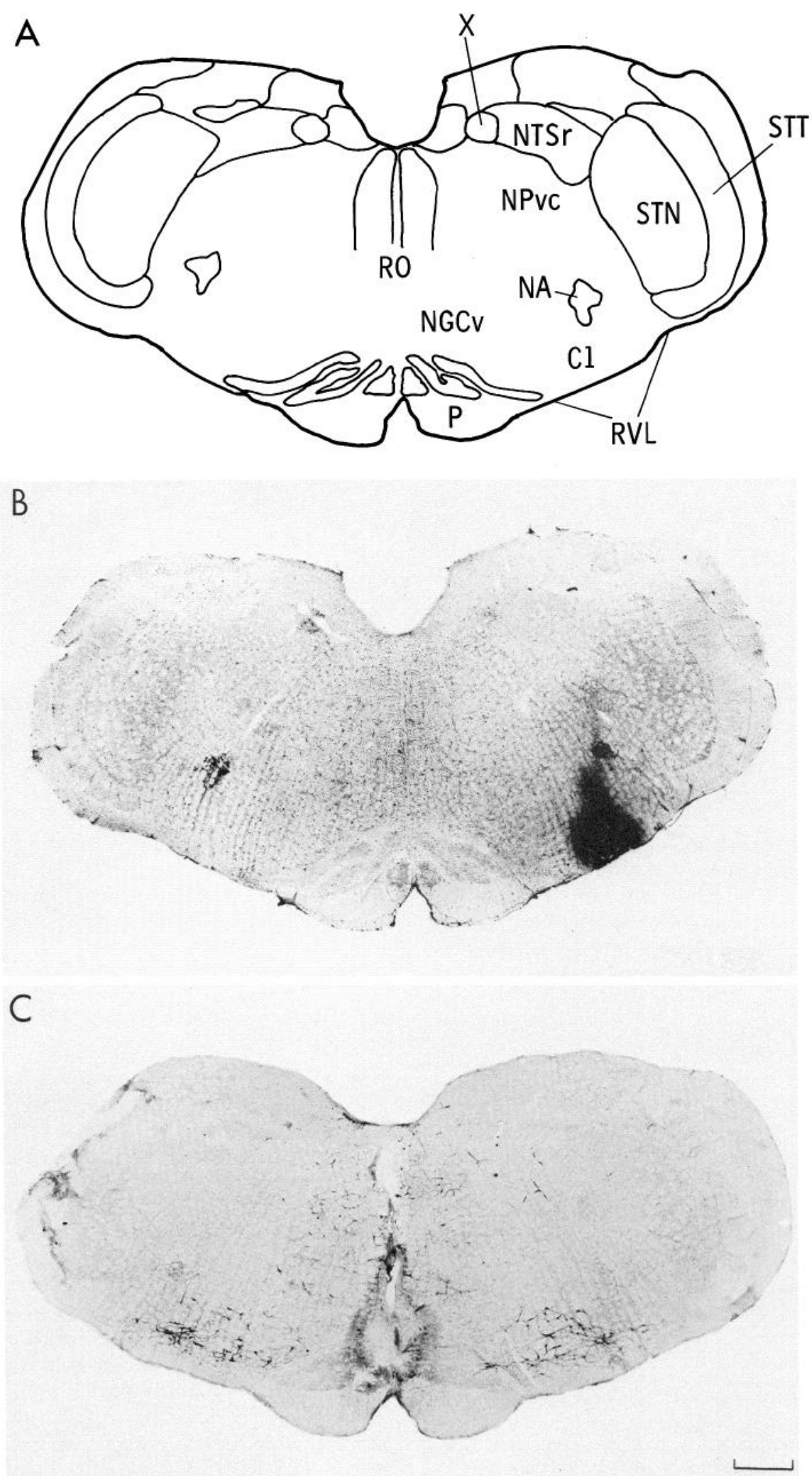

Figure 6. Distribution of electrolytic lesions on representative coronal sections through the rostral medulla $(A)$ stained immunocytochemically for CAT $(B)$ and PNMT $(C)$. A, Camera lucida drawing of a coronal section through the rostral medulla corresponding to the anteroposterior level of electrolytic lesions. $B$, Typical effective lesion site located in the rostral ventrolateral medulla underlying the nucleus ambiguus and corresponding to the $\mathrm{Cl}$ area of PNMT-labeled cell bodies $(C)$. Bilateral lesions at this site blocked the pressor response to systemically administered PHY. $C$, Representative ineffective lesion of the ventral raphe located medially to PNMT-immunoreactive neurons of the C1 area. Lesions at this site failed to alter the pressor response to physostigmine. Abbreviations: $C 1$, area of the rostral ventrolateral medulla containing PNMT-immunoreactive perikarya; $N A$, nucleus ambiguus; $N G C v$, nucleus gigantocellularis pars ventralis; $N P v c$, nucleus reticularis parvocellularis; $N T S r$, nucleus tractus solitarii, rostral division; $P$, pyramid; $R V L$, nucleus reticularis rostroventrolateralis; $S T N$, spinal trigeminal nucleus; STT, spinal trigeminal tract. Scale bar, $640 \mu \mathrm{m}$. 


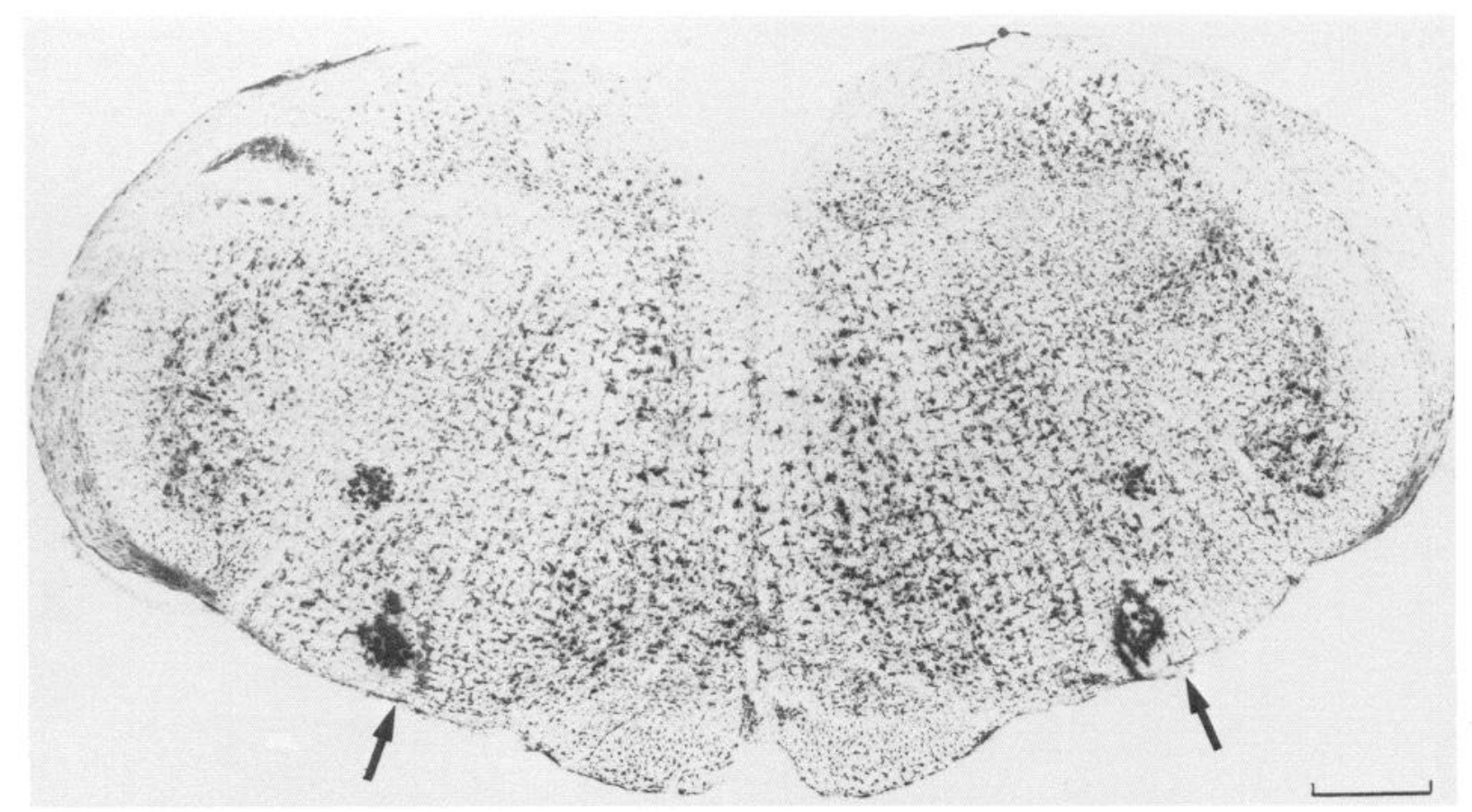

Figure 7. Location of microinjection sites in a representative experiment in which kainic acid ( $1 \mathrm{nmol} / \mathrm{side})$ abolished the pressor response to systemic injection of PHY (refer to Table 2). In this thionin-stained coronal section through the nucleus reticularis rostroventrolateralis $(R V L)$, bilateral deposition of India ink marks the physiologically characterized sites. Note the localization to an area of the RVL underlying the nucleus ambiguus. Arrows indicate the position of the micropipette tip. Compared with adjacent coronal sections labeled with PNMT, effective injection sites overlapped immunopositive perikarya. Injections of kainic acid into the nonadrenergic raphe region had no effect. Scale bar, $665 \mu \mathrm{m}$.

fectiveness of the baroreceptor reflex inhibition of these cells. PHY did not change the firing rate of noncardiovascular neurons in the RVL $(n=3)$. Such neurons were not antidromically activated from the spinal cord and were unaffected by activation of the baroreceptor reflex. These findings indicate that the sympathoexcitation evoked by i.v. administration of PHY is associated with a selective activation of reticulospinal cardiovascular neurons in the $\mathrm{Cl}$ area of the RVL.

\section{Effect of muscarinic blockade on the RVL neuronal responses to $P H Y$}

Intravenous injection of SCOP $(1 \mathrm{mg} / \mathrm{kg})$ at the peak of PHY response promptly reversed all of the PHY-induced excitatory effects (Fig. 2C). Splanchnic SNA and AP were reduced to control levels in all 5 animals (Fig. 2C). In 4 of 5 RVL-spinal sympathoexcitatory neurons tested, the augmented discharge frequency returned to $94 \pm 9 \%(n=4)$ of the pre-PHY firing rate. In the remaining case, SCOP produced no change in RVL

Table 3. Changes in mean arterial pressure and discharge frequency of RVL-spinal sympathoexcitatory neurons during systemic administration of PHY

\begin{tabular}{lccl} 
& Control & After PHY & Change \\
\hline MAP (mm Hg) & $78 \pm 9$ & $123 \pm 4$ & $+45 \pm 7^{a}$ \\
$\begin{array}{l}\text { RVL neuron mean firing } \\
\text { rate (spikes/sec) }\end{array}$ & $4.3 \pm 2.1$ & $9.3 \pm 2.9$ & $+5 \pm 0.9^{a}$
\end{tabular}

Maximum changes in mean arterial pressure (MAP) and discharge frequency were recorded in urethane-anesthetized rats $(n=8) 3-5$ min after i.v. injection of PHY $(100 \mu \mathrm{g} / \mathrm{kg})$.

a Significant difference from control $(p<0.001)$. unit activity. These findings indicate that muscarinic antagonism of the sympathoexcitation elicited by PHY involves decreased activity of RVL-spinal vasomotor neurons. This is consistent with the possibility that a population of muscarinic receptors is localized within the $\mathrm{Cl}$ area and mediates the sympathoexcitatory actions of $\mathrm{PHY}$.

\section{Receptor mechanisms in the $\mathrm{C} 1$ area mediating the vasopressor response to $\mathrm{PHY}$}

Effects of local injection of hexamethonium and SCOP

The nicotinic antagonist hexamethonium $(3 \mathrm{nmol})$ or the muscarinic antagonist SCOP ( $3 \mathrm{nmol})$ was microinjected into the $\mathrm{C} 1$ area bilaterally and PHY injected i.v. 5-10 min following administration of the anticholinergic agent.

Hexamethonium $(n=4)$ or vehicle $(n=5)$ had no effect on resting AP or the cardiovascular responses to PHY (Table 4, Fig. 9). In contrast, SCOP $(n=5)$ reduced the pressor response to PHY to $22 \%$ of untreated controls and abolished the late tachycardia while preserving the early bradycardiac response (Table 4, Fig. 9). We have previously demonstrated that local injection of SCOP elicits a gradual decrease in AP over the course of $30 \mathrm{~min}$ (Giuliano et al., 1986). Within the 5-10 min pretreatment period of this study, SCOP reduced AP $22 \pm 12$ $\mathrm{mm} \mathrm{Hg}$, although this value failed to achieve statistical significance $(p>0.05)$. Bilateral microinjection of SCOP into the nuclei raphe magnus and obscurus $(n=4)$ (Table 4$)$ or systemic administration of a comparable dose of SCOP $(6 \mathrm{nmol}, \mathrm{i} . \mathrm{v}$.$) had$ no effect on resting AP or the response to PHY $(+38 \pm 2 \mathrm{~mm}$ $\mathrm{Hg}$ before vs. $+40 \pm 5 \mathrm{~mm} \mathrm{Hg}$ after $6 \mathrm{nmol}$ i.v. SCOP; $p>$ $0.05, n=4$ ), indicating that the actions of SCOP were not due to spread of the drug or leakage to the periphery.

Effective sites of SCOP microinjection were localized to the 

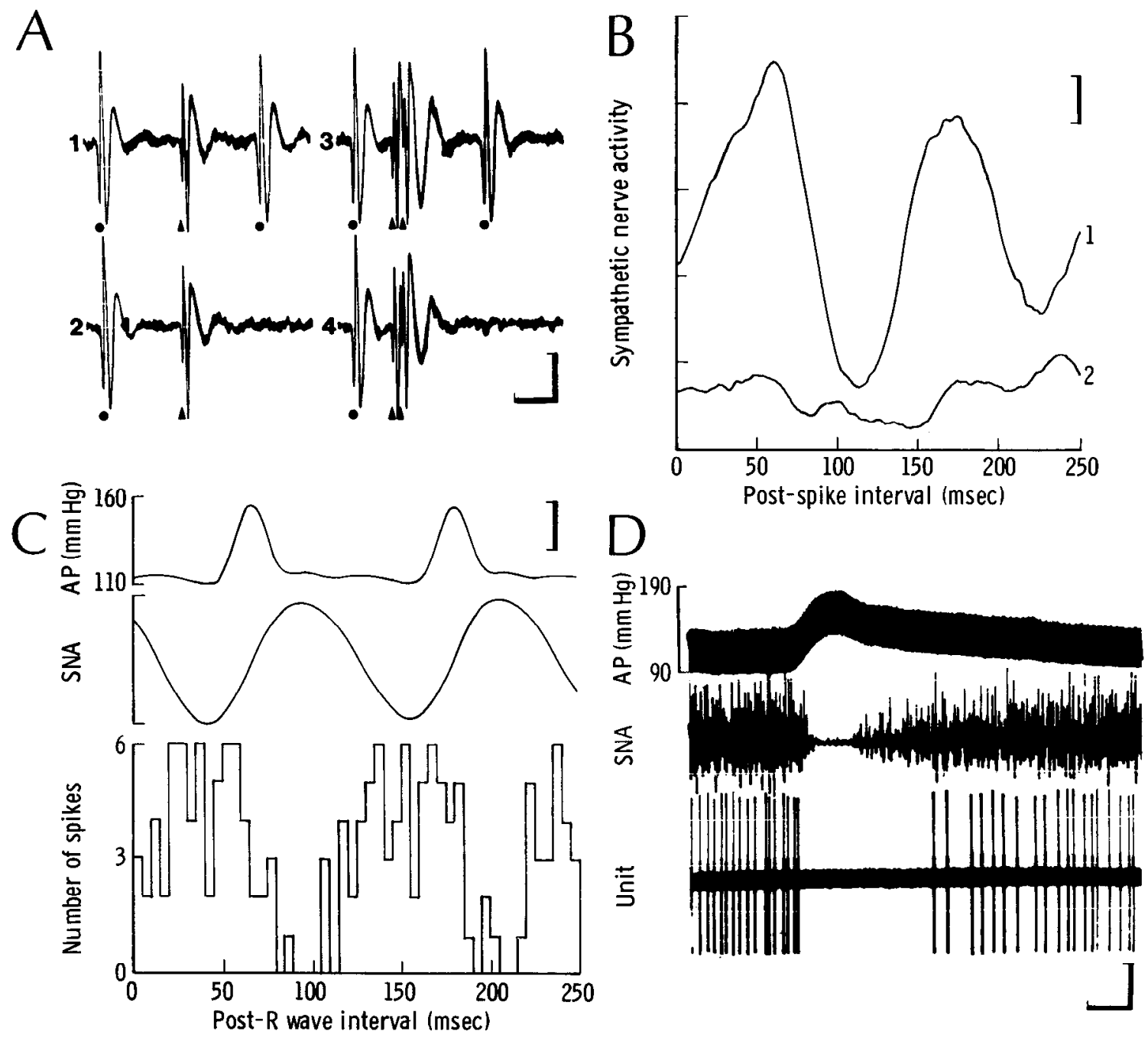

Figure 8. A, Five superimposed oscilloscopic traces of the responses of an RVL neuron to IML stimulation: filled circles below each panel indicate unit action potentials, filled triangles indicate stimulus artifacts. $A 1$, Spinal stimuli delivered at $12.8 \mathrm{msec}$ after a spontaneous unit spike evoked a constant onset latency response in the RVL neuron with an onset of $11.4 \mathrm{msec} . A 2$, No unit response was recorded when spinal stimuli were delivered $12.2 \mathrm{msec}$ following a spontaneous action potential. $A 3$, Because of collision between the spontaneous unit spike and the unit response evoked by the first shock, only a single unit rcsponse (to the sccond stimulus) was recorded when paired spinal stimuli $1.4 \mathrm{msec}$ apart were delivered $6.0 \mathrm{msec}$ after a spontaneous spike. A4, No unit response was recorded when the interstimulus interval was reduced to $1.3 \mathrm{msec}$. Vertical calibration, $200 \mu \mathrm{V}$; horizontal calibration, $6.0 \mathrm{msec}$. B. Average of splanchnic SNA following 135 spikes (time 0 ) of an RVL-spinal neuron (trace 1) and average of same SNA record triggered by random pulse train of same average frequency as RVL neuron (trace 2$)$. Bin width, 1 msec; vertical calibration, $10 \mu \mathrm{V}$. C, Post-R-wave averages (125 sweeps) of AP and SNA, and histogram of RVL-spinal unit discharges. Bin width, 1 msec for averages, $5 \mathrm{msec}$ for histogram; vertical calibration for SNA, $80 \mu \mathrm{V}$. $D$, Inhibition of spontaneous activity of RVL-spinal unit and SNA during phenylephrine-induced increase in AP. Horizontal calibration, $6 \mathrm{sec}$; vertical calibration: for unit, $160 \mu \mathrm{V} ;$ for SNA, $250 \mu \mathrm{V}$.

$\mathrm{C} 1$ area of the RVL ( $n=8$ ) as defined immunocytochemically. The centers of typical injection sites are illustrated in Figure 10. As shown in panels $A$ and $B$, the dye spot in the RVL marking the position of the pipette tip was surrounded by perikarya immunoreactive for PNMT. Using antibody to CAT, the microinjection sites were consistently localized within a field of CAT-containing processes that overlapped the $\mathrm{C} 1$ area (Fig. 10, $C, D$ ). Importantly, the higher magnification of the $\mathrm{Cl}$ area (Fig. $10 D$ ) reveals the presence of intensely labeled varicose processes immunoreactive for CAT scattered diffusely throughout the $\mathrm{Cl}$ region and immediately adjacent to the ventral surface of the RVL.

Effective injection sites also involved the more ventromedial aspect of the $\mathrm{Cl}$ region where CAT-labeled perikarya predominated and were admixed with PNMT-containing neurons.
However, injections at a similar level of the ventral medulla within the adjacent raphe magnus and obscurus complex, an area also containing muscarinic receptors (Ernsberger et al., $1988 \mathrm{a}, \mathrm{b}$ ) as well as cholinergic neurons and processes (Figs. 4, 5 ), were ineffective in antagonizing the rise in AP elicited by PHY.

\section{Controls for local anesthesia}

To rule out the possibility that the local actions of SCOP in the $\mathrm{Cl}$ area were nonspecific or related to a local anesthetic action, as has been attributed to atropine (Krnjevic, 1974), in 5 rats we examined the effect of local administration of SCOP on the pressor response to L-glutamate $(2 \mathrm{nmol})$ microinjected into the $\mathrm{Cl}$ area. Prior to SCOP, L-glutamate elicited an elevation of 37 $\pm 9 \mathrm{~mm} \mathrm{Hg}$. After SCOP the response to L-glutamate was pre- 


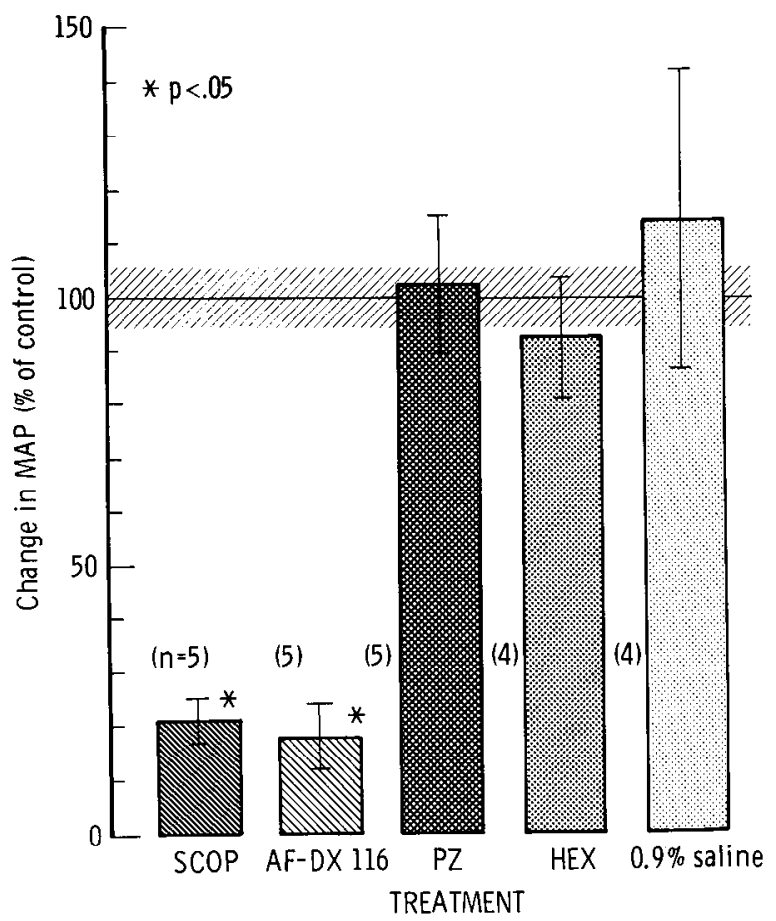

Figure 9. Effect of cholinergic antagonists bilaterally microinjected into the $\mathrm{Cl}$ area of the nucleus reticularis rostroventrolateralis $(R V L)$ on the pressor response to i.v. administration of PHY $(100 \mu \mathrm{g} / \mathrm{kg})$. The increase in mean arterial pressure $(M A P)$ evoked by PHY is expressed as a percentage of the control response. Thirty to $45 \mathrm{~min}$ after injection of PHY, microinjections ( $3 \mathrm{nmol}$ ) were made into the $\mathrm{Cl}$ area [SCOP, hexamethonium $(H E X)$, AF-DX 116, pirenzepine $(P Z)$, or $50 \mathrm{nl} 0.9 \%$ saline]. Five to ten minutes later, PHY was readministered. Only pretreatment with SCOP or AF-DX 116 significantly blocked the pressor response to $\mathrm{PHY}(p<0.05)$.

served (+38 $\pm 3 \mathrm{~mm} \mathrm{Hg}, p>0.05$ ). Thus, the actions of SCOP on AP could not be attributed to a nonspecific reduction of excitability of vasopressor neurons in the $\mathrm{Cl}$ area.

\section{Mapping the extent of diffusion}

To further establish that the actions of microinjected SCOP were topographically related to the $\mathrm{Cl}$ arca, we mapped by quantitative in vivo autoradiography the diffusion of ${ }^{3} \mathrm{H}$-SCOP in the RVL in 2 rats $10 \mathrm{~min}$ after microinjection of $50 \mathrm{nl}$ in the $\mathrm{Cl}$ area of RVL (see Materials and Methods). This interval corresponds to the maximal time elapsed between microinjection of the antagonist into the RVL and challenge with an i.v. injection of PHY.

Figure 11 shows a representative autoradiographic analysis of a section through the $\mathrm{Cl}$ area corresponding to the greatest extent of drug diffusion. The autoradiogram was digitized, shadecorrected, calibrated against ${ }^{3} \mathrm{H}$ standards, and linearly transformed into an equivalent scale of SCOP concentrations (Fig. $11 A$ ). The image was then partitioned into regions containing a specific range of concentrations (Fig. $11 B$ ). The effective site includes almost all of the $\mathrm{C} 1$ area and the surrounding RVL.

Figure 12 shows the distribution of SCOP concentration as a function of distance from the center of the injection. High concentrations of ${ }^{3} \mathrm{H}-\mathrm{SCOP}$ (up to $12.6 \mathrm{~mm}$ ) were present in close proximity to the micropipette tip. The concentration of ${ }^{3} \mathrm{H}$ SCOP fell off rapidly in the surrounding region down to back- ground levels. At a distance of $0.8 \mathrm{~mm}$ from the center of the injection, the optical density of the film was indistinguishable from that found outside the boundary of the brain section. The region containing the minimally detectable concentration of ${ }^{3} \mathrm{H}$ SCOP defined a circle in the plane of the section with a diameter of approximately $1.5 \mathrm{~mm}$. By examining thionin-stained sections adjacent to those used for autoradiography, it was possible to determine that the injections were centered within the $\mathrm{Cl}$ area (uttween the inferior olive and spinal trigeminal nucleus) coronally at the level of transition between the rostral (subvestibular) and intermediate (periventricular) thirds of the nucleus tractus solitarii. The anteroposterior level corresponded to a level $1.9 \mathrm{~mm}$ rostral to the calamus scriptorius. Detectable concentrations of the drug were present caudally only to the level of the area postrema. Rostrally, ${ }^{3} \mathrm{H}-\mathrm{SCOP}$ was absent at the level of the facial nucleus. Overall, the anteroposterior extent of the label was $980 \mu \mathrm{m}$. Thus, the volume of diffusion corresponded to an oblate spheroid of $0.87 \mathrm{~mm}^{3}$.

The concentration of SCOP necessary for total receptor blockade $(99.9 \%$ receptor occupancy) is approximated at $20 \mu \mathrm{M}$ using radioligand binding analysis of muscarinic receptors in ventrolateral medulla membranes (Giuliano et al., 1987). Thus, regions within $0.8 \mathrm{~mm}$ of the injection site in the $\mathrm{C} 1$ area contain sufficient SCOP to effect total receptor blockade (Fig. 11A). Since the brain was obtained at a time of effective antagonism of the PHY pressor response, the region containing high concentrations of SCOP, corresponding to the $\mathrm{C} 1$ area, probably represents the critical region for the physiological response. These findings indicate that the antimuscarinic action of locally injected SCOP (50 $\mathrm{nl})$ is highly localized to the C1 area of the RVL.

\section{Comparison of local $M_{1}$ - or $M_{2}$-muscarinic blockade on vasopressor responses to $P H Y$}

In the next study, we sought to define the muscarinic receptor subtype involved in the PHY-induced hypertensive response. We compared the actions of the $\mathbf{M}_{1}$-selective muscarinic receptor antagonist pirenzepine (Hammer et al., 1980; Watson et al., 1983) and the $\mathbf{M}_{2}$ muscarinic receptor antagonist AF-DX 116 (Giachetti et al., 1986; Hammer et al., 1986) microinjected into the $\mathrm{Cl}$ area on the pressor response to systemic $\mathrm{PHY}$.

AF-DX 116 injected bilaterally into the $\mathrm{Cl}$ area $(n=5)$, but not into the adjacent raphe $(n=4)$, blocked by over $80 \%$ the elevation in AP produced by systemic injection of PHY (Table 4, Fig. 9). It also blocked ( $n=2$ ) or substantially attenuated ( $n$ = 3) the initial bradycardiac effect of PHY but did not affect the later tachycardia (Table 4). Microinjection sites that blocked responses to PHY were distributed within the area of the RVL containing PNMT- and CAT-immunoreactive elements. That AF-DX 116 was acting locally was demonstrated by the observation that $\mathrm{i} . \mathrm{v}$. injection of a dose $(506 \mu \mathrm{g}) 200$ times the total dose delivered into the RVL had no effect on resting AP or HR or on the pressor $(+33 \pm 3$ before vs. $+37 \pm 1 \mathrm{~mm} \mathrm{Hg}$ after AF-DX 116) or cardiac ( $-20 \pm 6$ and $+30 \pm 6 \mathrm{bpm}$ before vs. $-15 \pm 2$ and $+20 \pm 4 \mathrm{bpm}$ after AF-DX 116) responses to PHY $(p<0.05, n=4)$.

Local microinjection of pirenzepine $(3 \mathrm{nmol})$ in the $\mathrm{Cl}$ area $(n=5)$ was without effect on resting AP and HR or on the pressor response to i.v. injection of PHY (Table 4, Fig. 9). However, the PHY-induced increase in HR was enhanced $(p<0.05)$ after treatment with pirenzepine (Table 4). 

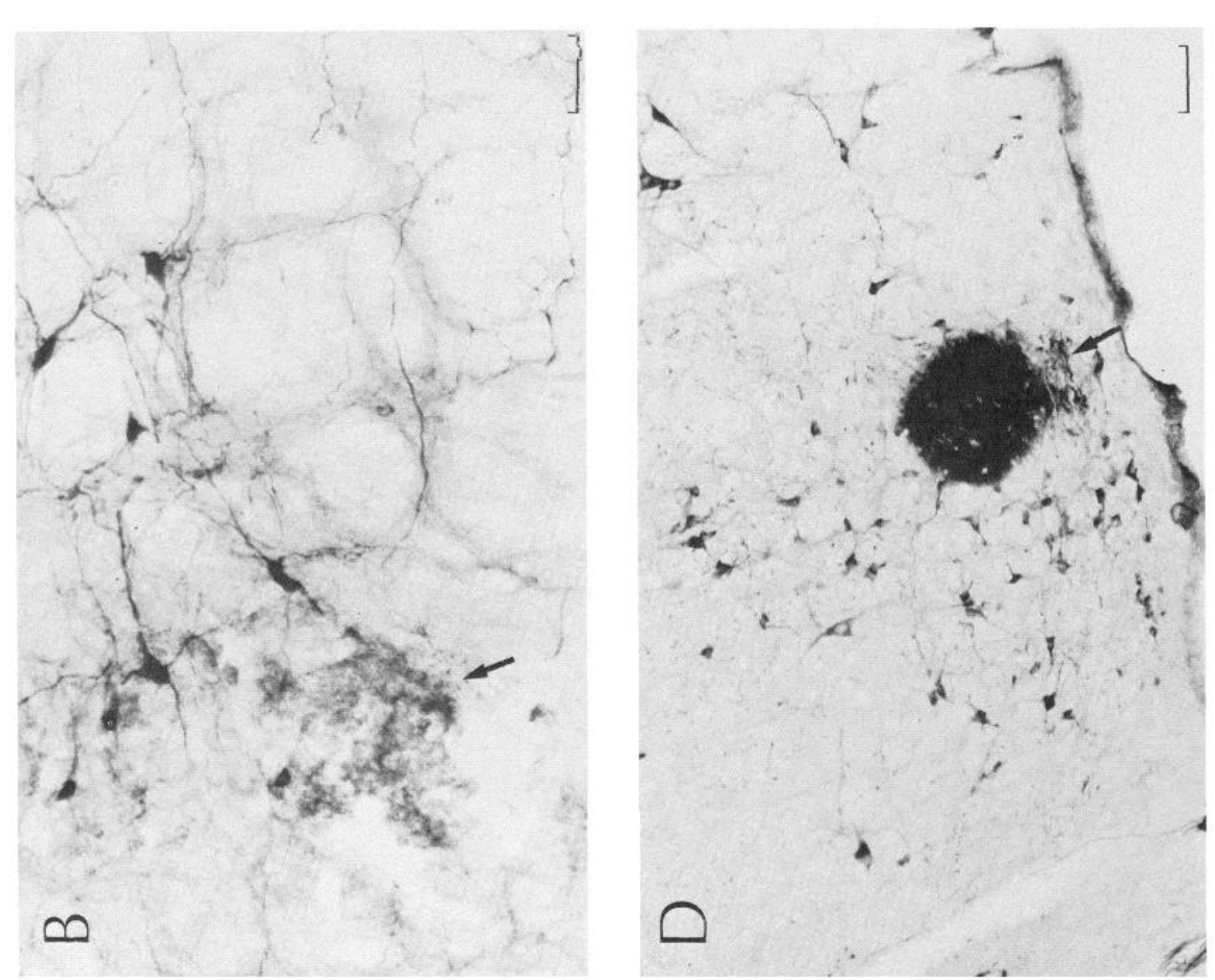

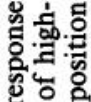

क्षे

造造

조음

च्

施它

능

象实

政

㲅

믕

क. 눙

름웡

.

I

¿늉.

空

뗭트 뭉

붕

牙它

홍

쿵

可

क⿺⿻一⿰冫⿰亅⿱丿丶丶⿱⿰㇒一乂
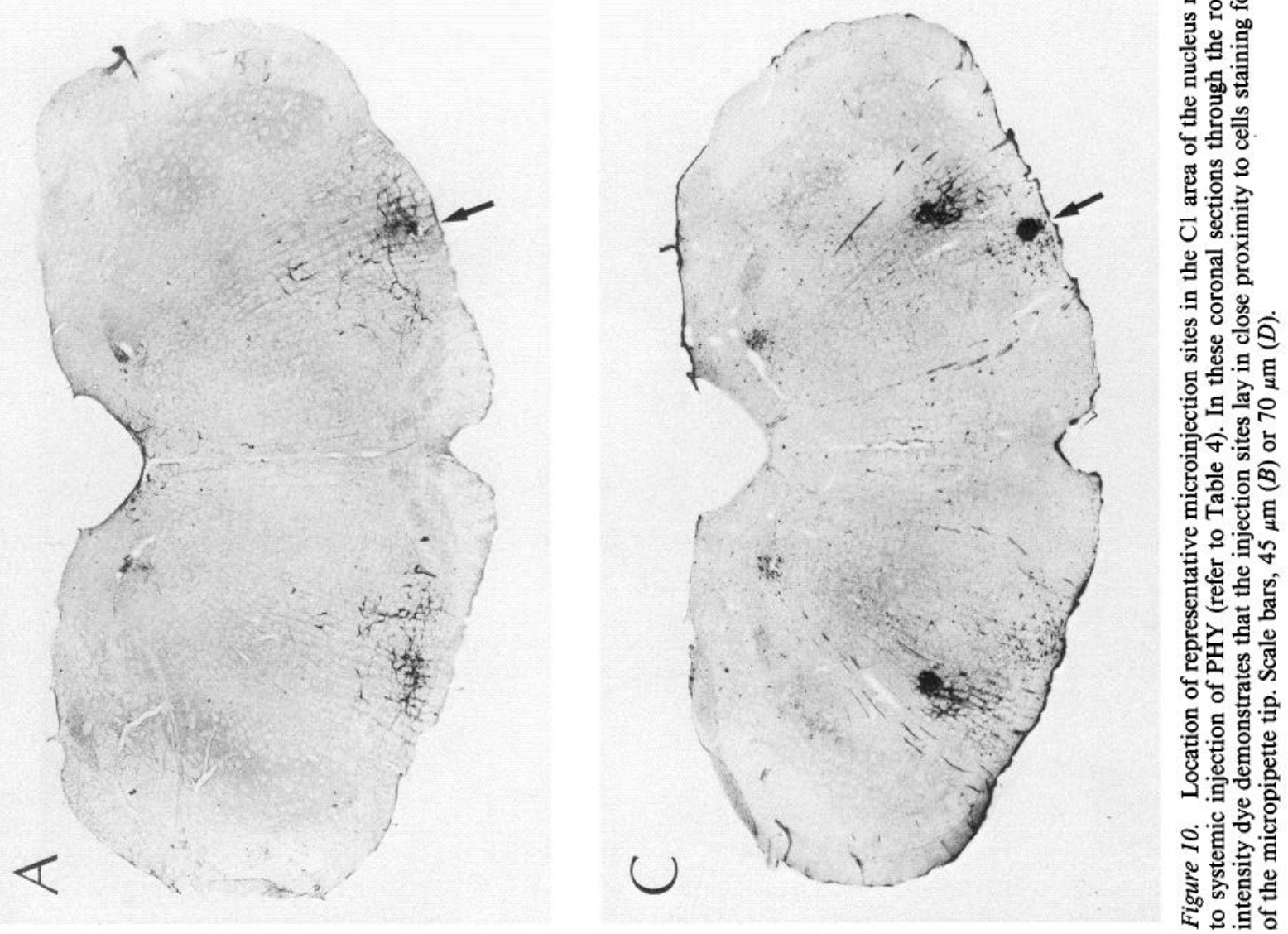


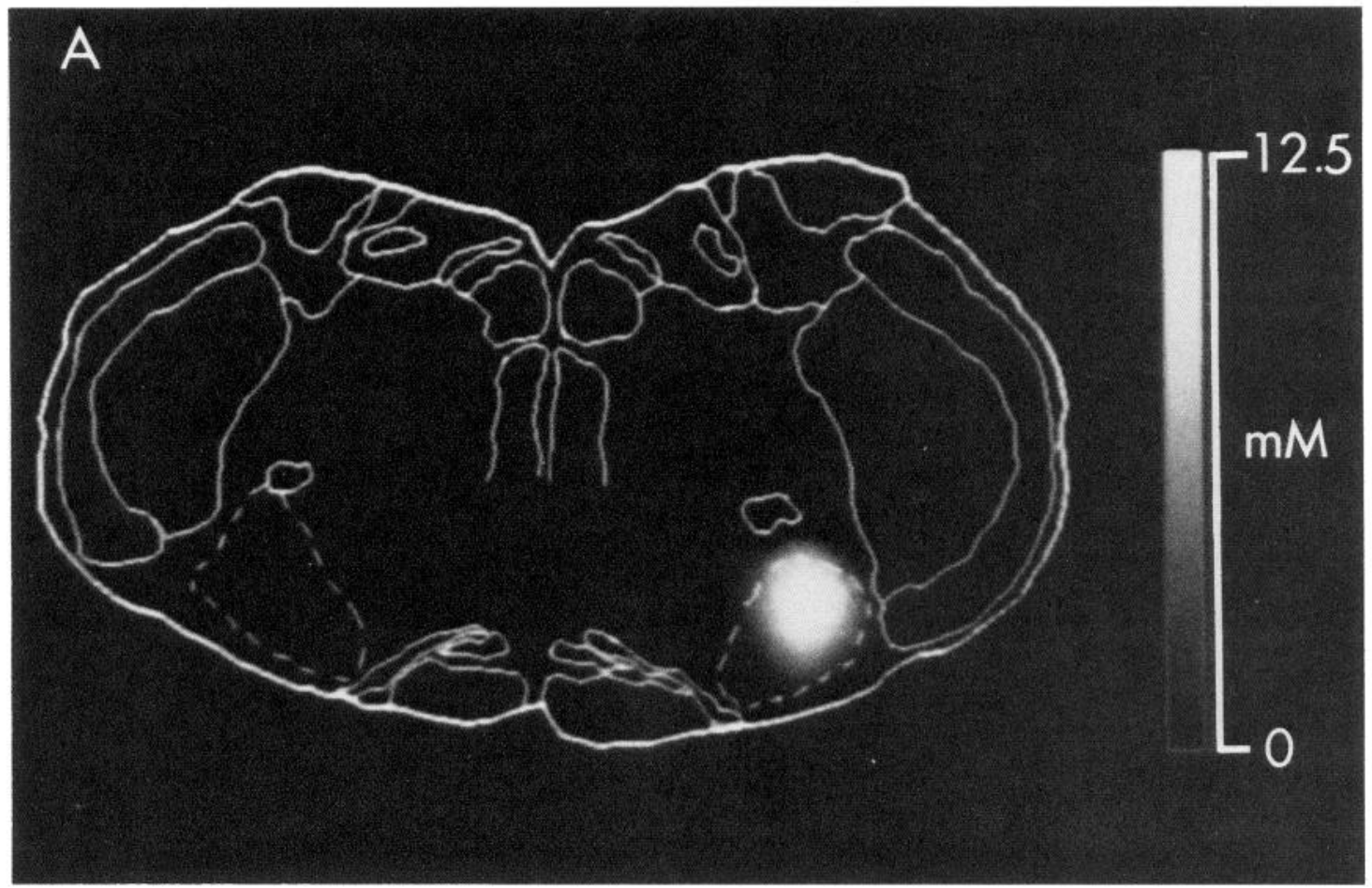

B

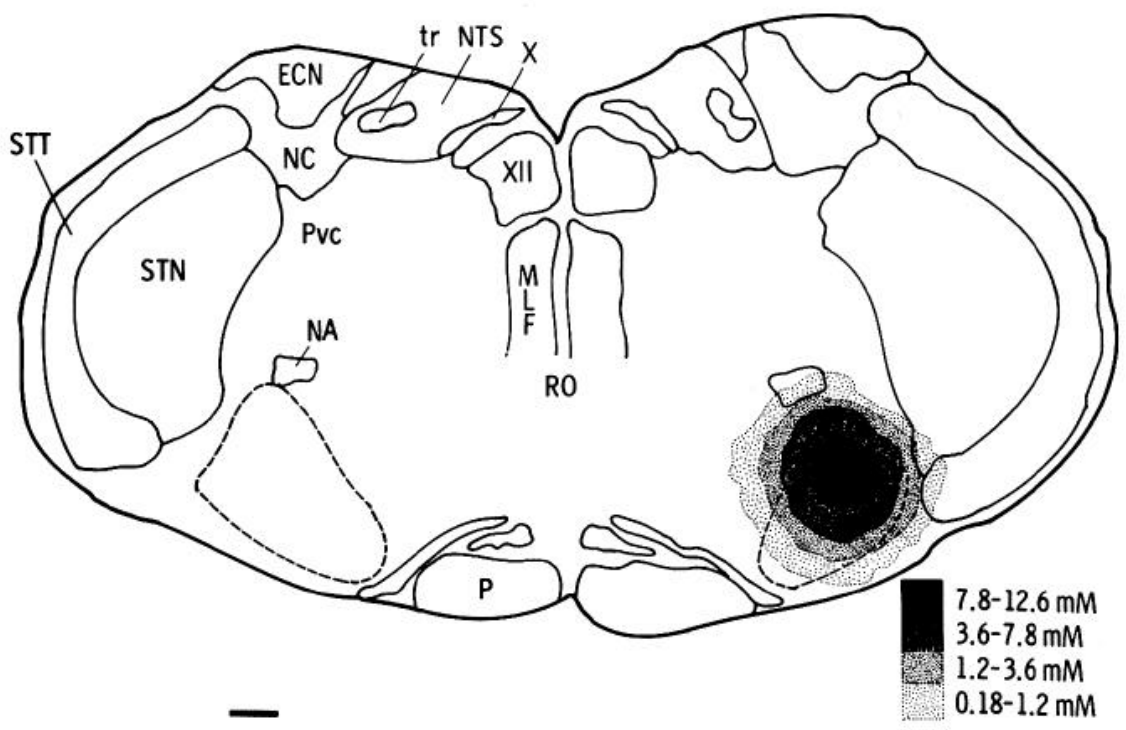

Figure 11. Distribution of ${ }^{3} \mathrm{H}-\mathrm{SCOP}$ microinjected into the nucleus reticularis rostroventrolateralis $(R V L)$ as determined by quantitative autoradiography. ${ }^{3} \mathrm{H}-\mathrm{SCOP}(N$-methyl derivative; $1 \mu \mathrm{Ci} / 3 \mathrm{nmol} / 50 \mathrm{nl})$ was injected unilaterally into the $R V L$. Ten minutes later, corresponding to the maximal interval between microinjection of the muscarinic antagonist and i.v. injection of PHY, the rat was decapitated, and the brain was frozen, sectioned, dried, and exposed to tritium-sensitive film for $9 \mathrm{~d}$. The digitized image of the autoradiogram is shown in $A$ superimposed on the outline of anatomical structures obtained from an adjacent thionin-stained section. The scale at right is in mM and was obtained by calibrating the image against autoradiographic standards (Geary and Wooten, 1983). The drawing in $B$ was derived from the digitized image by dividing the concentration scale into discrete ranges, as shown in the key at right. Concentrations of SCOP sufficient to block muscarinic receptors are almost entirely confined to the RVL. Scale bar, $300 \mu \mathrm{m}$.

\section{Effect of bilateral microinjection of $\mathrm{HC}-3$ into the $\mathrm{C} 1$ area on $\mathrm{PHY}$ pressor response}

The effect of inhibiting ACh synthesis in the $\mathrm{Cl}$ area on the pressor response to $\mathrm{PHY}$ was examined by microinjecting the high-affinity choline uptake inhibitor HC-3 (Kuhar and Murrin, 1978) bilaterally into the RVL. Within $60 \mathrm{~min}$ of bilateral microinjection, HC-3 (3 nmol), but not vehicle, decreased resting AP $21 \pm 6 \mathrm{~mm} \mathrm{Hg}$, (approximately $21 \% ; p<0.05, n=5$; Table $5)$, significantly blocked the pressor response to i.v. PHY (100 
Table 4. Effect of cholinergic antagonists microinjected bilaterally into the $\mathrm{C1}$ area on cardiovascular response to systemic PHY

\begin{tabular}{|c|c|c|c|c|c|c|}
\hline \multirow[b]{2}{*}{ Treatment } & \multirow[b]{2}{*}{$n$} & & \multicolumn{2}{|c|}{ Before treatment } & \multicolumn{2}{|c|}{ After treatment } \\
\hline & & & Baseline & $\begin{array}{l}\text { Response } \\
\text { to PHY }\end{array}$ & Baseline & $\begin{array}{l}\text { Response } \\
\text { to PHY }\end{array}$ \\
\hline Vehicle into $\mathrm{Cl}$ area & 5 & $\begin{array}{l}\text { MAP } \\
\text { HR }\end{array}$ & $\begin{array}{l}115 \pm 8.4 \\
354 \pm 30.3\end{array}$ & $\begin{array}{l}+33 \pm 3.4 \\
-38 \pm 6.6 \\
+46 \pm 9.3\end{array}$ & $\begin{array}{l}112 \pm 17.5 \\
343 \pm 17.9\end{array}$ & $\begin{array}{l}+41 \pm 8.7 \\
-59 \pm 18.5 \\
+75 \pm 18.9\end{array}$ \\
\hline $\mathrm{SCOP}$ into $\mathrm{Cl}$ area & 5 & $\begin{array}{l}\text { MAP } \\
\text { HR }\end{array}$ & $\begin{array}{l}110 \pm 7.2 \\
390 \pm 29.8\end{array}$ & $\begin{array}{l}+31 \pm 2.5 \\
-38 \pm 16.2 \\
+39 \pm 13.3\end{array}$ & $\begin{array}{r}89 \pm 12.9 \\
380 \pm 35.9\end{array}$ & $\begin{array}{r}+7 \pm 2.0^{a} \\
-58 \pm 31.6\end{array}$ \\
\hline SCOP into raphe area & 4 & $\begin{array}{l}\text { MAP } \\
\text { HR }\end{array}$ & $\begin{array}{l}108 \pm 1.4 \\
422 \pm 22.5\end{array}$ & $\begin{array}{l}+26 \pm 1.2 \\
-38 \pm 4.8 \\
+28 \pm 4.8\end{array}$ & $\begin{array}{c}95 \pm 9.5 \\
400 \pm 32.1\end{array}$ & $\begin{array}{l}+29 \pm 6.6 \\
-60 \pm 10.0 \\
+25 \pm 15.0\end{array}$ \\
\hline Hexamethonium into & & & $98 \pm 8.3$ & $+40 \pm 3.5$ & $93 \pm 17.1$ & $+38 \pm 7.8$ \\
\hline $\mathrm{Cl}$ area & 4 & $\begin{array}{l}\text { MAP } \\
\text { HR }\end{array}$ & $392 \pm 21.1$ & $\begin{array}{l}-35 \pm 9.6 \\
+53 \pm 13.1\end{array}$ & $435 \pm 29.6$ & $\begin{array}{l}-23 \pm 4.8 \\
+36 \pm 146\end{array}$ \\
\hline $\begin{array}{l}\text { AF-DX } 116 \\
\text { into } \mathrm{C} 1 \text { area }\end{array}$ & 5 & $\begin{array}{l}\text { MAP } \\
\text { HR }\end{array}$ & $\begin{array}{l}123 \pm 4.6 \\
422 \pm 14.6\end{array}$ & $\begin{array}{l}+39 \pm 4.3 \\
-50 \pm 8.4 \\
+12 \pm 1^{d}\end{array}$ & $\begin{array}{c}97 \pm 8.0^{b} \\
296 \pm 19.4^{b}\end{array}$ & $\begin{aligned}+8 & \pm 3.4^{a} \\
-20 & \pm 5.8^{b c} \\
+48 & \pm 18.0\end{aligned}$ \\
\hline $\begin{array}{l}\text { AF-DX } 116 \text { into } \\
\text { raphe area }\end{array}$ & 4 & $\begin{array}{l}\text { MAP } \\
\text { HR }\end{array}$ & $\begin{array}{c}98 \pm 4.3 \\
325 \pm 23.9\end{array}$ & $\begin{array}{l}+44 \pm 4.7 \\
-17 \pm 2.9 \\
+50 \pm 20\end{array}$ & $\begin{array}{r}94 \pm 6.6 \\
332 \pm 7.5\end{array}$ & $\begin{array}{l}+45 \pm 5.4 \\
-13 \pm 3.4 \\
+40 \pm 12.2\end{array}$ \\
\hline $\begin{array}{l}\text { Pirenzepine into } \mathrm{C} 1 \\
\text { area }\end{array}$ & 5 & $\begin{array}{l}\text { MAP } \\
\text { HR }\end{array}$ & $\begin{array}{l}113 \pm 7.5 \\
434 \pm 18.3\end{array}$ & $\begin{array}{l}+32 \pm 6.2 \\
-38 \pm 7.3 \\
+15 \pm 4.5\end{array}$ & $\begin{array}{l}107 \pm 8.4 \\
382 \pm 14.3^{b}\end{array}$ & $\begin{array}{l}+32 \pm 7.2 \\
-60 \pm 33.2 \\
+72 \pm 18.0^{a}\end{array}$ \\
\hline
\end{tabular}

Maximum changes in mean arterial pressure (MAP, $\mathrm{mm} \mathrm{Hg}$ ) and heart rate (HR, bpm) after i.v. injection of $\mathrm{PHY}$ (100 $\mu \mathrm{g} / \mathrm{kg}, \mathrm{i} . \mathrm{v}$.) were recorded in groups of urethane-anesthetized rats. Approximately $45 \mathrm{~min}$ later, when cardiovascular parameters returned to baseline, bilateral microinjections ( $3 \mathrm{nmol} / 50 \mathrm{nl}$ each side) were made into the C1 area (SCOP, hexamethonium, AF-DX 116 , pirenzepine, or $50 \mathrm{nl} 0.9 \% \mathrm{NaCl}$ ) or raphe region (SCOP, AF-DX 116). Five to ten min after treatment, each group (excepting AF-DX 116) was challenged with i.v. PHY and maximum changes in MAP and HR were recorded. Since AF-DX 116 profoundly lowered AP immediately after injection, PHY was not administered until AP stabilized at a level approaching baseline (50-60 min after treatment).

"Significant difference from pretreatment response $(p<0.05)$.

"Significant difference from pretreatment baseline $(p<0.05)$.

'Only $3 / 5$ rats showed a bradycardiac response.

"Only $3 / 5$ rats showed a tachycardiac response.

$\mu \mathrm{g} / \mathrm{kg}$ ), and substantially attenuated the hypertension elicited by the supramaximal dose of $1000 \mu \mathrm{g} / \mathrm{kg}(p<0.05, n=5)$ (Table 5, Fig. 13).

To demonstrate that $\mathrm{HC}-3$ diminished the availability of local $\mathrm{ACh}$ and had no direct postsynaptic actions, the pressor responses to unilateral intraparenchymal administration of PHY $(n=4)$ or carbachol were $(n=4)$ recorded before and $60 \mathrm{~min}$ after local administration of HC-3 (Fig. 14). Bilateral microinjection of HC-3 ( $3 \mathrm{nmol}$ ) into the $\mathrm{Cl}$ area did not affect the magnitude of the hypertensive response to the direct-acting agonist carbachol $(1 \mathrm{nmol})$, indicating that the responsiveness of cholinergic receptors was unaltered. However, $\mathrm{HC}-3$ pretreatment of the $\mathrm{C} 1$ area prevented the rise in AP produced by microinjection of the indirect-acting cholinergic agonist PHY

Table 5. Effect of hemicholinium-3 (HC-3) microinjected into the $\mathrm{Cl}$ area on pressor response to systemically administered PHY

\begin{tabular}{|c|c|c|c|c|c|}
\hline \multirow[b]{3}{*}{ Treatment } & \multirow[b]{3}{*}{$n$} & \multicolumn{4}{|c|}{ MAP $(\mathrm{mm} \mathrm{Hg})$} \\
\hline & & \multirow[b]{2}{*}{ Resting } & \multirow{2}{*}{$\begin{array}{l}\text { Baseline after } \\
\text { treatment }\end{array}$} & \multicolumn{2}{|c|}{ Response to PHY } \\
\hline & & & & $100 \mu \mathrm{g} / \mathrm{kg}$ & $1000 \mu \mathrm{g} / \mathrm{kg}$ \\
\hline Vchicle into $\mathrm{Cl}$ arca & 4 & $109 \pm 7.4$ & $105 \pm 7.4$ & $+37 \pm 6.2$ & $+67 \pm 4.3$ \\
\hline HC-3 into $\mathrm{C} 1$ area & 5 & $124 \pm 7.4$ & $102 \pm 6.6^{a}$ & $+11 \pm 3.1^{b}$ & $+46 \pm 5.1^{b}$ \\
\hline
\end{tabular}

HC-3 (3 ninol) or velicle ( $50 \mathrm{nl} 0.9 \%$ saline) was microinjected bilaterally into the $\mathrm{Cl}$ area of the RVL. Sixty min later baseline AP was recorded and responses to i.v. injection of PHY were recorded (the doses were separated by $30-45$ min).

${ }^{a} p<0.05$ compared with resting MAP.

" $p<0.05$ compared with vehicle-treated group. 


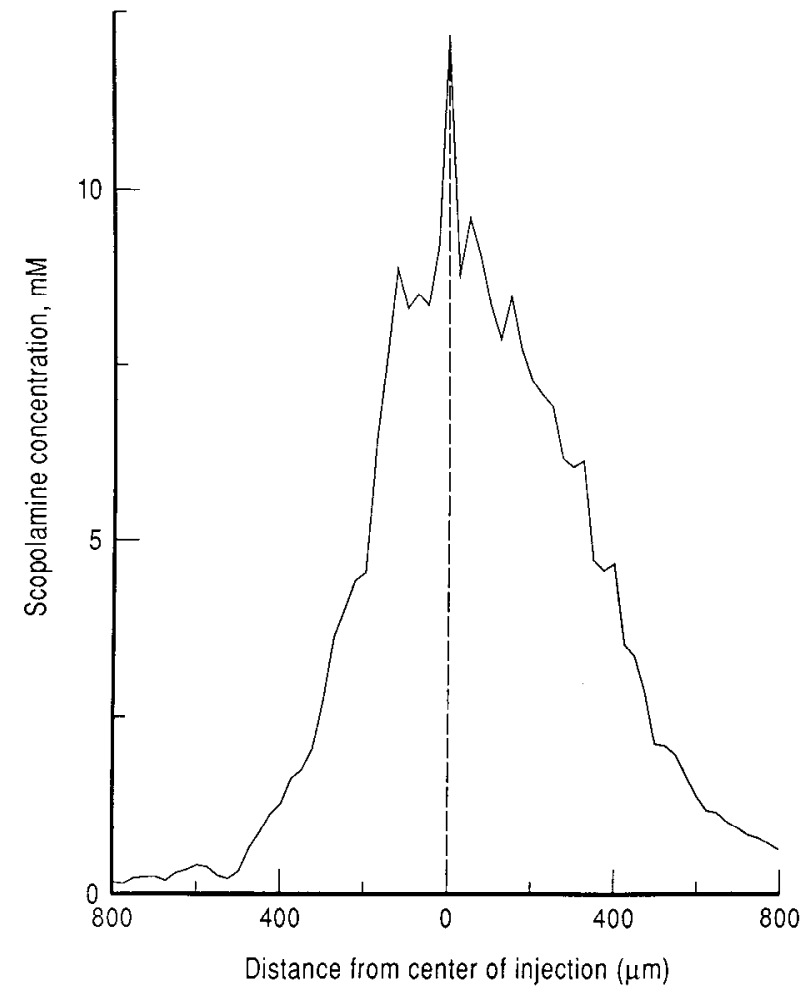

Figure 12. Concentration of SCOP (mM) in the nucleus reticularis rostroventrolateralis $(R V L)$ following local microinjection as a function of distance from the center of the injection $(\mu \mathrm{m})$. Data were derived from the digitized autoradiogram in Figure 11 by sampling a horizontal band $90 \mu \mathrm{m}$ thick centered on the region containing the highest apparent concentration of SCOP, which was defined as the center of injection. The band was divided into $30 \mu \mathrm{m}$ segments (corresponding to a single pixel of the image) and the mean SCOP concentration within each segment was calculated and plotted as a function of distance from the center of injection. Note the steep decline in concentration outside the original injection site (see Fig. 11 for details).

( $1 \mathrm{nmol})$ into the same site. This finding is consistent with the view that $\mathrm{HC}-3$ acted by reducing the availability of locally released $\mathrm{ACh}$ in the $\mathrm{Cl}$ area. The pressor response to microinjection of L-glutamate after carbachol or PHY was unaffected by prior administration of $\mathrm{HC}-3$, indicating the absence of nonspecific effects.

\section{Discussion}

In the present study we have demonstrated that the site of sympathoexcitatory action of PHY, wherein endogenously released ACh may influence AP, corresponds to the $\mathrm{C} 1$ area of the RVL. Until this study it had not been established anatomically that the $\mathrm{C} 1$ area contains cholinergic neurons and/or processes. However, the pressor responsiveness of the $\mathrm{Cl}$ area to indirect-acting (PHY), as well as direct-acting (carbachol), cholinergic agonists (Benarroch et al., 1986b; Giuliano et al., 1986, 1987) presumes an endogenous source of $\mathrm{ACh}$ in this major autonomic control area. That ACh is a transmitter in the region is supported not only by the presence of the cholinergic biosynthetic enzyme CAT, releasable pools of ACh (Arneric et al., 1986; Ernsberger et al., 1988b), and muscarinic cholinergic receptors (Ernsberger et al., 1988a, b), but also by the ultrastructural demonstration that CAT-immunoreactive terminals synapse upon RVL neurons (Milner et al., 1987a).

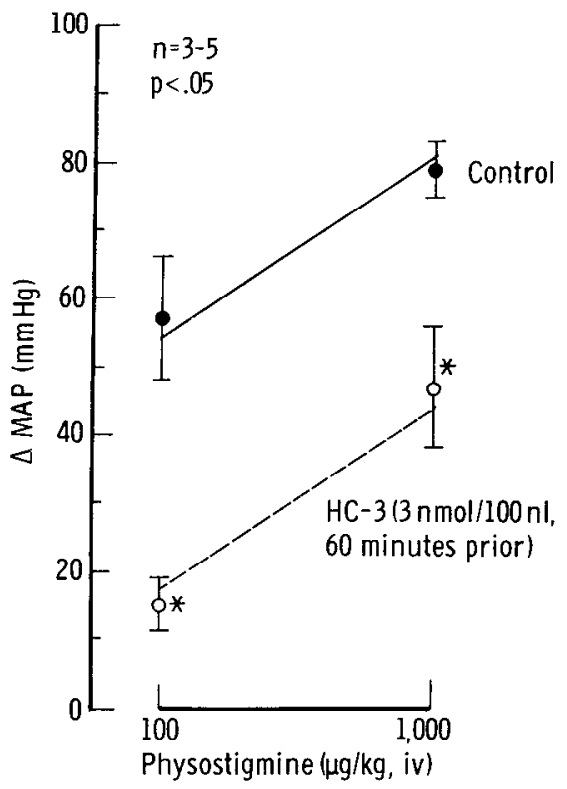

Figure 13. Effect of prior bilateral microinjection of hemicholinium-3 ( $H C-3 ; 3 \mathrm{nmol}$ ) into the $\mathrm{Cl}$ area of the nucleus reticularis rostroventrolateralis $(R V L)$ on the pressor response to systemically administered PHY. Compared with vehicle-pretreated controls, pretreatment (60 min) with $\mathrm{HC}-3$ significantly attenuated the increase in AP produced by i.v. injection of $100 \mu \mathrm{g} / \mathrm{kg}$ or $1000 \mu \mathrm{g} / \mathrm{kg}$ PHY.

In the present investigation we established that (1) cholinergic mechanisms mediating sympathoexcitation from the RVL are localized to the region containing the $\mathrm{C} 1$ adrenaline-synthesizing cell bodies; (2) a local plexus of cholinergic processes, a potential source of $A C h$, is present in the area; and (3) the $M_{2}$ muscarinic receptor subtype mediates the pressor effects of PHY. This study therefore provides functional and anatomical evidence of cholinergic innervation of the $\mathrm{Cl}$ area of the $\mathrm{RVL}$.

\section{Localization of the response to $P H Y$ in the $C l$ area}

Three lines of evidence indicate that the site of action of systemically administered PHY is within the C1 area of the RVL and that the elevations of AP, HR, and SNA produced by i.v. administration of PHY are mediated by activation of vasomotor neurons within the RVL.

First, sympathoexcitatory responses to PHY were abolished by bilateral electrolytic lesions or local microinjection of KA, both highly restricted to the $\mathrm{Cl}$ area. Disappearance of the response cannot be attributed to nonspecific effects of the lesions or injections since unilateral destruction of the region or control microinjections of KA into the adjacent midline raphe had no effect. Nor can the effects of bilateral inactivation of RVL neurons be attributed to the associated fall of AP, since responses to PHY could not be restored when normotensive levels of AP were maintained by continuous infusion of phenylephrine. The fact that the perikaryal-selective excitotoxic agent $\mathrm{KA}$ injected into the $\mathrm{C} 1$ area mimicked the effects of electrolytic lesions indicates that local neurons, and not fibers passing through the region, mediate the actions of PHY.

Second, microinjection of SCOP into the RVL blocked the pressor response to i.v. PHY. By analyzing the distribution of radiolabeled SCOP microinjected into the RVL with autoradiographic methods, we were able to demonstrate directly that effective concentrations of the drug capable of blocking the ac- 
tions of systemic PHY were confined to the boundaries of the $\mathrm{Cl}$ area. These results not only validate the high resolution of our microinjection technique, but also implicate neurons of the $\mathrm{C} 1$ area in mediating the response to PHY.

Third, i.v. PHY produced an increase in spontaneous activity of reticulospinal vasomotor neurons in the $C 1$ area concomitant with increases in SNA and AP. It is generally accepted that the $\mathrm{RVL}$ is the location of sympathetic premotor neurons directly involved in cardiovascular control: (1) Vasomotor neurons of the RVL, including $\mathrm{Cl}$ adrenergic neurons, terminate exclusively within the IML throughout all levels of the thoracic spinal cord (Ross et al., 1981, 1984a) and synapse directly on sympathetic preganglionic neurons (Milner et al., 1988a). (2) Their spontaneous activity is related directly to the discharge of sympathetic nerves (Brown and Guyenet, 1984; Barman and Gebber, 1985; Morrison et al., 1988). (3) They are innervated and inhibited tonically and phasically by baroreceptor input from the NTS (Brown and Guyenet, 1984; Barman and Gebber, 1985; Morrison et al., 1988; Ruggiero and Reis, 1988). (4) They coincide with a dense cluster of PNMT-containing neurons of the C1 group (Granata et al., 1985; Morrison et al., 1988). Thus, our findings support the interpretation that vasomotor neurons of the RVL mediate the sympathoexcitatory effects of systemically administered PHY.

\section{Source of $A C h$ in the $C l$ area}

That the vasopressor response to PHY is mediated by neurons in the $\mathrm{Cl}$ area and is blocked locally by muscarinic antagonists implies that the response is mediated by increased local accumulation of $\mathrm{ACh}$, presumably from an endogenous source. The assumption that local release of $\mathrm{ACh}$ is essential for the action of PHY is supported by our finding that vasopressor responses to PHY administered systemically or by microinjection into the $\mathrm{C} 1$ area were reduced by the local administration of $\mathrm{HC}-3$, which selectively inhibits high-affinity choline transport into nerve terminals (Kuhar and Murrin, 1978). HC-3 binds specifically at presynaptic cholinergic nerve terminals (Quirion, 1985) in known cholinergic regions of the rat brain (Rainbow et al., 1984) and depletes neuronal stores of ACh (Freeman et al., 1979; Buccafusco and Spector, 1980) by blocking the re-uptake carrier system that supplies precursor for $\mathrm{ACh}$ synthesis. The finding that local administration of $\mathrm{HC}-3$ blocked the pressor response to locally or systemically administered PHY, but not that to local carbachol, indicates that $\mathrm{HC}-3$ acted presynaptically to reduce the synthesis and, hence, availability of $\mathrm{ACh}$ in the $\mathrm{C} 1$ area. An intact response to carbachol also precludes a direct postsynaptic action of HC-3 at muscarinic binding sites (Speth and Yamamura, 1979). Thus, the effects of HC-3 microinjected into the $\mathrm{C} 1$ area suggest a functionally significant local source of $\mathrm{ACh}$ in the RVL. This interpretation is consistent with both our pharmacological demonstration of the efficacy of muscarinic receptor blockade in the $\mathrm{Cl}$ area and our anatomical observations of CAT-immunoreactive elements in the same region.

By examining the distribution of CAT-labeled processes and perikarya in the RVL relative to that of PNMT-containing neurons, we discovered that the $\mathrm{Cl}$ area and its surround in the RVL are innervated by a rich plexus of bouton-like varicose processes. We also identified heretofore unrecognized CAT-immunoreactive perikarya adjacent to and partially overlapping the $\mathrm{C} 1$ area in the medial aspect of the RVL and lining the ventral medullary surface. Although other studies have mapped cholinergic neurons in the lower brain stem (Armstrong et al.,

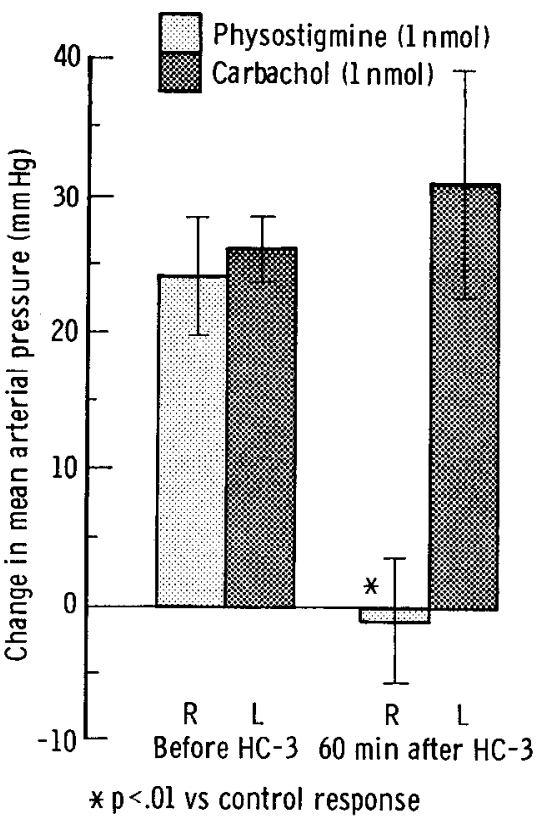

Figure 14. Effect of prior bilateral microinjection of hemicholinium-3 (HC-3;3 nmol) into the $\mathrm{C} 1$ area of the nucleus reticularis rostroventrolateralis $(R V L)$ on pressor responses to local microinjection of cholinergic agonists. Control pressor responses to unilateral microinjection into the $\mathrm{C} 1$ area of $1 \mathrm{nmol}$ carbachol (left) and $1 \mathrm{nmol} \mathrm{PHY} \mathrm{(right)} \mathrm{were}$ obtained $(n=4)$. After AP recovered to baseline, HC-3 was bilaterally microinjected into the $\mathrm{C} 1$ area. Sixty minutes later, unilateral microinjections of cholincrgic agonists werc repcated. Pretrcatment with $\mathrm{HC}-3$ completely abolished the pressor response to PHY, whereas the magnitude of the pressor response to carbachol was unaltered.

1983; Houser et al., 1983; Satoh et al., 1983), none have described cholinergic cell bodies or processes in this region. This localization of immunoreactive CAT in the $C 1$ area corresponds to the distribution of catalytically active enzyme measured in micropunches of the RVL (Arneric et al., 1986; Ernsberger et al., 1988b) and sites from which $\mathrm{ACh}$ can be released from micropunches by depolarization (Arneric et al., 1986), evidence strongly supporting the view that the identified terminals are the source of endogenous ACh.

Most cholinergic neurons in the RVL were not admixed with the PNMT-immunoreactive cells, but were localized to contiguous regions of the RVL ventromedial to the adrenergic cell cluster and lining the ventral medullary surface. This observation then raises the question of the source of the cholinergic terminals in the $\mathrm{Cl}$ area. One possibility is that they arise locally from intrinsic CAT-labeled neurons adjacent to the $\mathrm{Cl}$ area, since retrograde tracers injected into the $\mathrm{C} 1$ area transport to local neurons, as well as distally (Ruggiero et al., 1984; Ross et al., 1985). The terminals might also arise from other nuclei containing cholinergic neurons (Armstrong et al., 1983; Houser et al., 1983; Satoh et al., 1983; Ruggiero et al., 1987) that project to the RVL, including the laterodorsal tegmental nucleus, the nucleus tractus solitarii, and the spinal cord (Ruggiero et al., 1984, 1986; Ross et al., 1985).

\section{Receptor mechanisms}

This study has demonstrated that the sympathoexcitatory actions of systemically administered PHY are mediated by an action of locally released $\mathrm{ACh}$ on muscarinic receptors localized to the $\mathrm{Cl}$ area of the RVL. Our results confirm earlier obser- 
vations that the pressor effects of PHY administered intravenously or intraparenchymally are unaffected by the nicotinic antagonist hexamethonium, but can be prevented by systemic administration of muscarinic antagonists (Brezenoff and Giuliano, 1982; Willette et al., 1984) or their local microinjection/ ventral surface application in the pressor area of the VLM (Willette et al., 1984; Benarroch et al., 1986b; Punnen et al., 1986). The unaltered pressor response to local microinjection of the excitatory amino acid L-glutamate following microinjection of SCOP suggests that blockade of the PHY response was not due to a nonspecific or local anesthetic action of SCOP, as has been attributed to atropine (Krnjevic, 1974).

Using pharmacological probes, we further defined the muscarinic receptor subtype within the RVL that mediates the sympathoexcitatory response to PHY. Muscarinic receptors are heterogeneous and can be separated into at least 2 subtypes (Watson et al., 1983), which differ in their tissue distribution and ligand specificity. Neuronal $M_{1}$ receptors-localized, for example, in sympathetic ganglia, cerebral cortex, and hippocampus (Hammer et al., 1980; Giraldo et al., 1987; Wang et al., 1987)-are blocked selectively by pirenzepine (Hammer et al., 1980; Watson et al., 1983), while $M_{2}$ receptors-concentrated within the brain stem and cerebellum (Giraldo et al., 1987; Wang et al., 1987) - are preferentially blocked by the novel $\mathrm{M}_{2}$-selective antagonist AF-DX 116 (Giachetti et al., 1986; Hammer et al., 1986).

We observed that cardiovascular responses to PHY were blocked by local microinjections of AF-DX 116, but not pirenzepine, into the $\mathrm{Cl}$ area. Thus, it is the $\mathrm{M}_{2}$ subclass of muscarinic receptors within the $\mathrm{Cl}$ area that appears to mediate the increase in AP elicited by PHY. Our findings agree with the results of direct ligand binding studies (Giuliano et al., 1987) and quantitative receptor autoradiography (Ernsberger et al., 1988a) that $\mathrm{M}_{2}$ receptors predominate in the RVL and that $\mathrm{M}_{2}$ receptors mediate the pressor response to the selective agonist oxotremorine microinjected into the $\mathrm{C} 1$ area (Giuliano et al., 1987). Since central cholinergic mechanisms may be altered in hypertensive states (Brezenoff and Giuliano, 1982; McCaughran et al., 1983; Giuliano and Brezenoff, 1987), the involvement of $\mathrm{M}_{2}$ receptors in the pressor effect of PHY suggests that selective $\mathrm{M}_{2}$ antagonists capable of crossing the blood-brain barrier might be useful as centrally acting antihypertensive agents without interfering with memory or other cognitive functions subserved by forebrain regions (Amaral, 1987) containing $\mathbf{M}_{1}$ receptors.

\section{$A C h$ and the microcircuitry of the $C 1$ area}

Collectively, the data from this and other studies (see introductory remarks for references) indicate that $\mathrm{ACh}$ is synthesized, stored, and released from cholinergic processes in the region and acts via $\mathrm{M}_{2}$ muscarinic receptors to excite reticulospinal sympathoexcitatory neurons. Consequently, the activity of preganglionic sympathetic neurons in the IML is increased and AP and $\mathrm{HR}$ are elevated.

Whether the excitatory action of $\mathrm{ACh}$ is upon RVL-reticulospinal neurons or is indirect by an action on an interposed neuron is not known. In addition to adrenergic cell bodies (Hökfelt et al., 1974; Ruggiero et al., 1985b), the $\mathrm{Cl}$ area also contains neurons synthesizing GABA (Meeley et al., 1985; Ruggiero et al., 1985a), enkephalin (Milner et al., 1986), substance P (Lorenz et al., 1985; Milner et al., 1988b), neuropeptide Y (Hökfelt et al., 1983; Blessing et al., 1987), and thyrotropin-releasing hormone (Helke et al., 1986), some possibly colocalized within adrenergic cells (Hökfelt et al., 1983; Lorenz et al., 1985; Blessing et al., 1987). Microinjection and iontophoretic studies also have established that many of these agents modify AP when microinjected into the RVL or applied onto the adjacent ventral medullary surface (Willette et al., 1983a, b, 1984; Ross et al., 1984b; Sun and Guycnct, 1985, 1986a, b; Bcnarroch ct al., 1986b; Punnen and Sapru, 1986).

ACh is well known to increase mammalian brain cell excitability via muscarinic receptors (Krnjevic, 1974). Conceivably, therefore, ACh could act as an excitatory neurotransmitter by directly depolarizing spinally projecting vasomotor neurons or indirectly activating excitatory local interneurons. In halothaneanesthetized rats, iontophoretic application of ACh weakly excites spinally projecting vasomotor neurons in the rostral region of the $\mathrm{C} 1$ adrenergic cell group (Sun and Guyenet, 1986a). While our results are consistent with a direct action of $\mathrm{ACh}$ on RVL vasomotor neurons, confirmation of this hypothesis requires iontophoretic application of PHY.

Alternatively, ACh may inhibit an inhibitory local neuron. $\mathrm{ACh}$ has been shown to hyperpolarize some central neurons, possibly via $\mathrm{M}_{2}$ receptors (McCormick and Prince, 1985; Egan and North, 1986). By augmenting the inhibition of a tonic inhibitory input (e.g., GABAergic) to $\mathrm{C} 1$ area vasomotor neurons, ACh could increase reticulospinal drive, and hence elevate SNA, AP, and HR. This interpretation is supported by several lines of evidence: (1) The $\mathrm{Cl}$ area is richly innervated by GABAergic neurons and terminals that synthesize, store, and release GABA (Meeley et al., 1985; Ruggiero et al., 1985a, 1987); (2) there is evidence that GABA is tonically released in the $\mathrm{C} 1$ area, since local injection of the GABA antagonist bicuculline results in a potent elevation of AP and HR (Ross et al., 1984b); (3) GABA directly inhibits reticulospinal sympathoexcitory neurons in the RVL, as demonstrated iontophoretically (Sun and Guyenet, 1985, 1986b) and by microinjection studies (Willette et al., 1983b; Ross et al., 1984b); (4) recent ultrastructural immunocytochemical studies (Milner et al., 1987b) indicate that PNMT-containing neurons of the $\mathrm{Cl}$ area are richly innervated by GABAcontaining terminals that establish symmetric and hence inhibitory (Cohen et al., 1982) synapses; (5) comparable ultrastructural studies have demonstrated that in the RVL the majority $(77 \%)$ of synaptic contacts made by cholinergic terminals are not upon PNMT-immunoreactive neurons, but upon unlabeled cells containing noncatecholaminergic transmitters, synapses that are predominantly symmetric and thereby presumably inhibitory (Milner et al., 1987a).

In summary, this study expands the transmitter pool that may contribute to the cardiovascular regulatory functions of the RVL. A neuroanatomical substrate for a role of $\mathrm{ACh}$ in $\mathrm{AP}$ regulation by the RVL has been established. That treatment of the RVL with $\mathrm{HC}-3$ decreases resting AP and bilaterally microinjected SCOP results in a gradual fall in resting AP (Arneric et al., 1986; Giuliano et al., 1986) suggests that cholinergic neurons have some, albeit probably a minor, contribution to the tonic regulation of AP. Yet to be investigated is the role of $\mathrm{ACh}$ in the numerous cardiovascular reflexes that depend upon the integrity of the region (Dampney and Moon, 1980; Willette et al., 1983b; Granata et al., 1985; Sun and Guyenet, 1985; Stornetta et al., 1989).

\section{References}

Amaral, D. G. (1987) Memory: Anatomical organization of candidate brain regions. In Handbook of Physiology-The Nervous System V, 
2nd ed., V. B. Mountcastle, ed., pp. 211-294, Williams \& Wilkins, Baltimore.

Armstrong, D. M., C. B. Saper, A. I. Levey, B. H. Wainer, and R. D. Terry (1983) Distribution of cholinergic neurons in rat brain: Demonstrated by the immunocytochemical localization of choline acetyltransferase. J. Comp. Neurol. 216: 53-68.

Arneric, S. P., R. Giuliano, P. Ernsberger, M. D. Underwood, and D. J. Reis (1986) Does acetylcholine released within the $\mathrm{Cl}$ area of the rostral ventrolateral medulla (RVL) tonically maintain arterial pressure? Fed. Proc. 45: 3422

Barman, S. M., and G. L. Gebber (1985) Axonal projection patterns of ventrolateral medullospinal sympathoexcitatory neurons. J. Neurophysiol. 53: 1551-1566.

Benarroch, E. E., A. R. Granata, R. Giuliano, and D. J. Reis (1986a) Neurons of the $\mathrm{Cl}$ area of rostral ventrolateral medulla mediate NTS hypertension. Hypertension (Suppl. 2) 8: I56-I60.

Benarroch, E. E., A. R. Granata, D. A. Ruggiero, D. H. Park, and D. J. Reis $(1986 \mathrm{~h})$ Neurons of the $C .1$ area mediate cardiovascular responses initiated from the ventral medullary surface. Am. J. Physiol. 250: R932-R945.

Blessing, W. W., J. R. Oliver, A. H. Hodgson, T. H. Joh, and J. D. Willoughby (1987) Neuropeptide Y-like immunoreactive C1 neurons in the rostral ventrolateral medulla of the rabbit project to sympathetic preganglionic neurons in the spinal cord. J. Auton. Nerv. Syst. 18: 121-129.

Brezenoff, H. E., and R. Giuliano (1982) Cardiovascular control by cholinergic mechanisms in the central nervous system. Annu. Rev. Pharmacol. Toxicol. 22: 341-381.

Brown, D. L., and P. G. Guyenet (1984) Cardiovascular neurons of brain stem with projection to spinal cord. Am. J. Physiol. 247: R 1009R1016.

Buccafusco, I. J., and S. Spector (1980) Role of central cholinergic neurons in experimental hypertension. J. Cardiovasc. Pharmacol. 2: $347-355$.

Ciriello, J., M. M. Caverson, and C. Polosa (1986) Function of the ventrolateral medulla in the control of the circulation. Brain. Res. Rev. 11: 359-391.

Cohen, R. S., R. K. Carlin, D. J. Grab, and P. Siekevitz (1982) Phosphoproteins in postsynaptic densities. Prog. Brain Res. 56: 49-76.

Coyle, J. T., M. E. Molliver, and M. J. Kuhar (1978) In situ injection of kainic acid: A new method for selectively lesioning neural cell bodies while sparing axons of passage. J. Comp. Neurol. 180: 301324.

Curtis, D. R., and R. Malik (1985) A neurophysiological analysis of the effect of kainic acid on nerve fibres and terminals in the cat spinal cord. I. Physiol. (Lond.) 368: 99-108.

Dampney, R. A. L., and E. A. Moon (1980) Role of ventrolateral medulla in vasomotor response to cerebral ischemia. Am. J. Physiol. 239: H349-H358.

Dev, N. B., and H. H. Loeschcke (1979) Topography of the respiratory and circulatory responses to acetylcholine and nicotine on the ventral surface of the medulla oblongata. Pfluegers Arch. 379: 19-27.

Eckenstein, F., and H. Thoenen (1982) Production of specific antisera and monoclonal antibodies to choline acetyltransferase: Characterization and use for identification of cholinergic neurons. EMBO J. 1 : 363-368.

Eckenstein, F., Y. A. Barde, and H. Thoenen (1981) Production of specific antibodies to choline acetyltransferase purified from pig brain. Neuroscience 6: 993-1000.

Egan, T. M., and R. A. North (1986) Acetylcholine hyperpolarizes central neurones by acting on an $\mathbf{M}_{2}$ muscarinic receptor. Nature 319: $405-407$.

Ernsberger, P., V. Arango, and D. J. Reis (1988a) A high density of muscarinic receptors in the rostral ventrolateral medulla is revealed by correction for autoradiographic efficiency. Neurosci. Lett. 85: 179186.

Ernsberger, P., S. P. Arneric, V. Arango, and D. J. Reis (1988b) Quantitative distribution of muscarinic receptors and choline acetyltransferase in rat medulla: Examination of transmitter-receptor mismatch. Brain Res. 452: 336-344.

Freeman, J. J., J. R. Macri, R. L. Choi, and D. J. Jenden (1979) Studies on the behavioral and biochemical effects of hemicholinium in vivo. J. Pharmacol. Exp. Ther. 210:91-97.

Geary, W. A., and G. F. Wooten (1983) Quantitative film autoradiography of opiate agonist and antagonist binding in rat brain. $J$. Pharmacol. Exp. Ther. 225: 234-240.
Gebber, G. L., and S. M. Barman (1981) Sympathetic-related activity of brain stem neurons in baroreceptor-denervated cats. Am. J. Physiol. 240: R348-R355.

Giachetti, A., R. Micheletti, and E. Montagna (1986) Cardioselective profile of AF-DX 116, a muscarine $\mathbf{M}_{2}$ receptor antagonist. Life Sci. 38: 1663-1672.

Giraldo, E., R. Hammer, and H. Ladinsky (1987) Distribution of muscarinic receptor subtypes in rat brain as determined in binding studies with AF-DX 116 and pirenzepine. Life Sci. 40: 833-840.

Giuliano, R., and H. E. Brezenoff (1987) Increased central cholinergic activity in rat models of hypertension. J. Cardiovasc. Pharmacol. 10 . $113-122$.

Giuliano, R., P. Ernsberger, V. Arango, D. Ruggiero, and D. J. Reis (1986) Cholinergic mechanisms in rostral ventrolateral medulla (RVL) participate in the tonic control of arterial pressure (AP) and mediate vasopressor action of systemically administered physostigmine. Soc. Neurosci. Abstr. 12: 964.

Giuliano, R., P. Ernsberger, and D. J. Reis (1987) Cholinergic vasopressor mechanism in rostral ventrolateral medulla is mediated by the $\mathrm{M}_{2}$ muscarinic receptor subtype. Soc. Neurosci. Abstr. 13: 808 .

Goodchild, A. K., R. A. L. Dampney, and R. Bandler (1982) A method for evoking physiological responses by stimulation of cell bodies, but not axons of passage within localized regions of the central nervous system. J. Neurosci. Methods 6: 351-363.

Gootman, P. M., M. I. Cohen, M. P. Piercey, and P. Wolotsky (1975) A search for medullary neurons with activity patterns similar to those in sympathetic nerves. Brain Res. 87: 395-406.

Granata, A. R., D. A. Ruggiero, D. H. Park, T. H. Joh, and D. J. Reis (1985) Brain stem area with $\mathrm{Cl}$ epinephrine neurons mediates baroreflex vasodepressor responses. Am. J. Physiol. 248: H547-H567.

Guertzenstein, P. G. (1973) Blood pressure effects obtained by drugs applied to the ventral surface of the brain stem. J. Physiol. (I ond.) 229: 395-408

Hammer, R., C. P. Berrie, W. J. M. Birdsall, A. S. V. Burgen, and E. C. Hulme (1980) Pirenzepine distinguishes between different subclasses of muscarinic receptors. Nature 283: 90-92.

Hammer, R., E. Giraldo, G. B. Schiavi, E. Monferini, and M. Ladinsky (1986) Binding profile of a novel cardioselective muscarine receptor antagonist, AFDX 116, to membranes of peripheral tissues and brain in the rat. Life Sci. 38: 1653-1662.

Helke, C. J., S. C. Sayson, J. K. Keeler, and C. G. Charlton (1986) Thyrotropin-releasing hormone-immunoreactive neurons project from the ventral medulla to the intermediolateral cell column: Partial coexistence with serotonin. Brain Res. 381: 1-7.

Hökfelt, T., K. Fuxe, M. Goldstein, and O. Johansson (1974) Immunohistochemical evidence for the existence of adrenaline neurons in the rat brain. Brain Res. 66: 235-251.

Hökfelt, T., J. M. Lundberg, K. Tatemoto, V. Mutt, L. Terenius, J. Polak, S. Bloom, C. Sasek, R. Elde, and M. Goldstein (1983) Neuropeptide Y (NPY) and FMRFamide neuropeptide-like immunoreactivities in catecholamine neurons of the rat medulla oblongata. Acta Physiol. Scand. 117: 315-318.

Houser, C. R., G. D. Crawford, R. P. Barber, P. M. Salvaterra, and J. E. Vaughn (1983) Organization and morphological characteristics of cholinergic neurons: An immunocytochemical study with a monoclonal antibody to choline acetyltransferase. Brain Res. 266: 97-119.

Iadecola, C., M. Nakai, S. Mraovitch, D. A. Ruggiero, L. W. Tucker, and D. J. Reis (1983) Global increase in cerebral metabolism and blood flow produced by focal electrical stimulation of dorsal medullary reticular formation in rat. Brain Res. 272: 101-114.

Joh, T. H., and M. Goldstein (1973) Isolation and characterization of multiple forms of phenylethanolamine N-methyltransferase. Mol. Pharmacol. 9: 117-129.

Joh, T. H., and M. E. Ross (1983) Preparation of catecholaminesynthesizing enzymes as immunogen for immunocytochemistry. In Methods in the Neurosciences (IBRO Handbook Series, Vol. 3), A. C. Cuello, ed., pp. 121-138, Wiley, New York.

Krnjevic, K. (1974) Chemical nature of synaptic transmission in vertebrates. Physiol. Rev. 54: 418-540.

Kuhar, M. J., and L. C. Murrin (1978) Sodium-dependent, high-affinity choline uptake. J. Neurochem. 30: 15-21.

Lipski, J. (1981) Antidromic activation of neurons as an analytic tool in the study of the central nervous system. J. Neurosci. Methods 4 : $1-32$

Lorenz, R. G., C. B. Saper, D. L. Wong, R. D. Ciaranello, and A. D. Loewy (1985) Colocalization of substance P- and phenylethanol- 
amine N-methyltransferase-like immunoreactivity in neurons of ventrolateral medulla that project to the spinal cord: Potential role in control of vasomotor tone. Neurosci. Lett. 55: 255-260.

McCaughran, J. A., Jr., D. Murphy, N. Schechter, and R. Friedman (1983) Participation of central cholinergic system in blood pressure regulation in the Dahl rat model of essential hypertension. J. Cardiovasc. Pharmacol. 5: 1005-1009.

McCormick, D. A., and D. A. Prince (1985) Two types of muscarinic response to acetylcholine in mammalian cortical neurons. Proc. Natl. Acad. Sci. USA 82: 6344-6348.

Meeley, M. P., D. A. Ruggiero, T. Ishitsuka, and D. J. Reis (1985) Intrinsic GABA neurons in the nucleus tractus solitarii and the rostral ventrolateral medulla of the rat: An immunocytochemical and biochemical study. Neurosci. Lett. 58: 83-89.

Milner, T. A., V. M. Pickel, T. H. Joh, and D. J. Reis (1986) Catecholaminergic neurons in the rostral ventrolateral medulla receive direct synapses from terminals with substance $\mathrm{P}$ and enkephalin-like immunoreactivity. Soc. Neurosci. Abstr. 12: 104.

Milner, T. A., V. M. Pickel, C. Abate, and D. J. Reis (1987a) Choline acetyltransferase in the rat rostral ventrolateral medulla: Ultrastructural localization and synaptic interactions with neurons containing catecholamine synthesizing enzymes. Soc. Neurosci. Abstr. 13: 808.

Milner, T. A., V. M. Pickel, J. Chan, V. J. Massari, W. H. Oertel, D. H. Park, T. H. Joh, and D. J. Reis (1987b) Phenylethanolamine $\mathrm{N}$-methyltransferase-containing neurons in the rostral ventrolateral medulla. II. Synaptic relationships with GABAergic terminals. Brain Res. 411: 46-57.

Milner, T. A., S. F. Morrison, C. Abate, and D. J. Reis (1988a) Phenylethanolamine $\mathrm{N}$-methyltransferase-containing terminals synapse directly on sympathetic preganglionic neurons in the rat. Brain Res. 448: 205-222.

Milner, T. A., V. M. Pickel, C. Abate, T. H. Joh, and D. J. Reis (1988b) Ultrastructural characterization of substance P-containing neurons in the rostral ventrolateral medulla in relation to neurons containing catecholamine synthesizing enzymes. J. Comp. Neurol. 270: 427445.

Morrison, S. F., T. A. Milner, and D. J. Reis (1988) Reticulospinal vasomotor ncurons of the rat rostral ventrolateral medulla: Rclationship to sympathetic nerve activity and the $\mathrm{Cl}$ adrenergic cell group. J. Neurosci. 8: 1286-1301.

Park, D. H., E. E. Baetge, B. Kaplan, V. R. Albert, D. J. Reis, and T. H. Joh (1982) Different forms of adrenal phenylethanolamine $\mathrm{N}$-methyltransferase: Species-specific posttranslational modification. J. Neurochem. 38: 410-414.

Paxinos, G., and C. Watson (1986) The Rat Brain in Stereotaxic Coordinates, 2nd ed., Academic, New York.

Punnen, S., and H. N. Sapru (1986) Cardiovascular responses to medullary microinjections of opiate agonists in uretbane-anesthetized rats. J. Cardiovasc. Pharmacol. 8: 950-956.

Punnen, S., R. N. Willette, A. J. Krieger, and H. N. Sapru (1986) Medullary pressor area: Site of action of intravenous physostigmine. Brain Res. 382: 178-184.

Quirion, R. (1985) Comparative localization of putative pre- and postsynaptic markers of muscarinic cholinergic nerve terminals in rat brain. Eur. J. Pharmacol. 111: 287-289.

Rainbow, T. C., B. Parsons, and M. Wieczorek (1984) Quantitative autoradiography of $\left[{ }^{3} \mathrm{H}\right]$-hemicholinium-3 binding sites in the rat brain. Eur. J. Pharmacol. 102: 195-196.

Reis, D. J., C. A. Ross, A. R. Granata, and D. A. Ruggiero (1987) Role of $\mathrm{Cl}$ area of rostroventrolateral medulla in cardiovascular control. In Brain Peptides and Catecholamines in Cardiovascular Regulation, J. P. Buckley and C. M. Ferrario, eds., pp. 1-14, Raven, New York.

Ross, C. A., D. M. Armstrong, D. A. Ruggiero, V. M. Pickel, T. H. Joh, and D. J. Reis (1981) Adrenaline neurons in the rostral ventrolateral medulla innervate thoracic spinal cord: A combined immunocytochemical and retrograde transport demonstration. Neurosci. Lett. 25: 257-262.

Russ, C. A., D. A. Ruggiero, T. H. Joh, D. H. Park, and D. J. Reis (1984a) Rostral ventrolateral medulla: Selective projections to the thoracic autonomic cell column from the region containing $\mathrm{C} 1$ adrenaline neurons. J. Comp. Neurol. 228: 168-184.

Ross, C. A., D. A. Ruggiero, D. H. Park, T. H. Joh, A. F. Sved, J. Fernandez-Pardal, J. M. Saavedra, and D. I. Reis (1984b) Tonic vasomotor control by the rostral ventrolateral medulla: Effect of electrical or chemical stimulation of the area containing $\mathrm{Cl}$ adrenaline neurons on arterial pressure, heart rate and plasma catecholamines and vasopressin. J. Neurosci. 4: 479-494.

Ross, C. A., D. A. Ruggiero, and D. J. Reis (1985) Projections from the nucleus tractus solitarii to the rostral ventrolateral medulla. J. Comp. Neurol. 242: 511-534.

Ruggiero, D. A., and D. J. Reis (1988) Epinephrine and cardiovascular function. In Epinephrine in the Central Nervous System, J. M. Stolk, D. C. U'Prichard, and K. Fuxe, eds., pp. 291-307, Oxford U. P., New York.

Ruggiero, D. A., C. A. Ross, M. Anwar, D. J. Reis (1984) The rostral ventrolateral medulla: Immunocytochemistry of intrinsic neurons and afferent connections. Soc. Neurosci. Abstr. 10: 299.

Ruggiero, D. A., M. P. Meeley, M. Anwar, and D. J. Reis (1985a) Newly identified GABAergic neurons in regions of the ventrolateral medulla that regulate blood pressure. Brain Res. 339: 171-177.

Ruggiero, D. A., C. A. Ross, M. Anwar, D. H. Park, T. H. Joh, and D. J. Reis (1985b) Distribution of neurons containing phenylethanolaminc $\mathrm{N}$-methyltransferase in medulla and hypothalamus of rat. $\mathrm{J}$. Comp. Neurol. 239: 127-154.

Ruggiero, D. A., R. L. Stornetta, S. F. Morrison, and D. J. Reis (1986) Spinal projections to brainstem autonomic centers. Soc. Neurosci. Abstr. 12: 1154

Ruggiero, D. A., R. Giuliano, and D. J. Reis (1987) Cholinergic neurons in autonomic brainstem nuclei. Fed. Proc. 46: 493.

Satoh, K., D. M. Armstrong, and C. Fibiger (1983) A comparison of the distribution of central cholinergic neurons as demonstrated by acetylcholinesterase pharmacohistochemistry and choline acetyltransferase immunohistochemistry. Brain Res. Bull. 11: 693-720.

Speth, R. C., and H. I. Yamamura (1979) On the ability of choline and its analogues to interact with muscarinic cholinergic receptors in the rat brain. Eur. J. Pharmacol. 58: 197-201.

Stcrnbcrger, L. A. (1979) Immunocytochemistry, Prentice-IIall, Englewood Cliffs, NJ.

Stornetta, R. L., S. F. Morrison, D. A. Ruggiero, and D. J. Reis (1989) Neurons of rostral ventrolateral medulla mediate somatic pressor reflex. Am. J. Physiol. (in press).

Sun, M.-K., and P. G. Guyenet (1985) GABA-mediated baroreceptor inhibition of reticulospinal neurons. Am. J. Physiol. 249: R672-R680.

Sun, M.-K., and P. G. Guyenet (1986a) Hypothalamic glutamatergic input to medullary sympathoexcitatory neurons in rats. Am. J. Physiol. 251: R798-R810.

Sun, M.-K., and P. G. Guyenet (1986b) Effect of clonidine and gammaaminobutyric acid on the discharges of medullo-spinal sympathoexcitatory neurons in the rat. Brain Res. 368: 1-17.

Swadlow, H. A. (1982) Antidromic activation: Measuring the refractory period at the site of axonal stimulation. Exp. Neurol. $75: 514$ 519.

Wang, J. X., W. R. Roeske, K. Gulya, W. Wang, and H. I. Yamamura (1987) [ $\left.{ }^{3} \mathrm{H}\right]-A F-D X 116$ labels subsets of muscarinic cholinergic receptors in rat brain and heart. Life Sci. 41: 1751-1760.

Watson, M., H. I. Yamamura, and W. R. Roeske (1983) A unique regulatory profile and regional distribution of $\left[{ }^{3} \mathrm{H}\right]$-pirenzepine in the rat provide evidence for distinct $\mathbf{M}_{1}$ and $\mathbf{M}_{2}$ muscarinic receptor subtypes. Life Sci. 32: 3001-3011.

Willette, R. N., P. P. Barcas, A. J. Krieger, and H. N. Sapru (1983a) Vasopressor and depressor areas in the rat medulla. Identification by microinjection of I-glutamate. Neuropharmacology 22: 1071-1079.

Willette, R. N., A. J. Krieger, P. P. Barcas, and H. N. Sapru (1983b) Medullary gamma-aminobutyric acid (GABA) receptors and the regulation of blood pressure in the rat. J. Pharmacol. Exp. Ther. 226 893-899.

Willette, R. N., S. Punnen, A. J. Krieger, and H. N. Sapru (1984) Cardiovascular control by cholinergic mechanisms in the rostral ventrolateral medulla. J. Pharmacol. Exp. Ther. 231: 457-463. 